University of Nebraska - Lincoln

DigitalCommons@University of Nebraska - Lincoln

2012

\title{
Polarimetric retrievals of surface and cirrus clouds properties in the region affected by the Deepwater Horizon oil spill
}

\author{
Matteo Ottaviani \\ NASA Goddard Institute for Space Studies \\ Brian Cairns \\ NASA Goddard Institute for Space Studies \\ Jacek Chowdhary \\ Columbia University \\ Bastiaan Van Diedenhoven \\ Columbia University \\ Kirk Knobelspiesse \\ NASA Goddard Institute for Space Studies \\ See next page for additional authors
}

Follow this and additional works at: https://digitalcommons.unl.edu/nasapub

Part of the Physical Sciences and Mathematics Commons

Ottaviani, Matteo; Cairns, Brian; Chowdhary, Jacek; Van Diedenhoven, Bastiaan; Knobelspiesse, Kirk; Hostetler, Chris; Ferrare, Rich; Burton, Sharon; Hair, John; Obland, Michael D.; and Rogers, Raymond, "Polarimetric retrievals of surface and cirrus clouds properties in the region affected by the Deepwater Horizon oil spill" (2012). NASA Publications. 77.

https://digitalcommons.unl.edu/nasapub/77

This Article is brought to you for free and open access by the National Aeronautics and Space Administration at DigitalCommons@University of Nebraska - Lincoln. It has been accepted for inclusion in NASA Publications by an authorized administrator of DigitalCommons@University of Nebraska - Lincoln. 


\section{Authors}

Matteo Ottaviani, Brian Cairns, Jacek Chowdhary, Bastiaan Van Diedenhoven, Kirk Knobelspiesse, Chris Hostetler, Rich Ferrare, Sharon Burton, John Hair, Michael D. Obland, and Raymond Rogers 


\title{
Polarimetric retrievals of surface and cirrus clouds properties in the region affected by the Deepwater Horizon oil spill
}

\author{
Matteo Ottaviani ${ }^{\text {a, } *}$, Brian Cairns ${ }^{\text {b }}$, Jacek Chowdhary ${ }^{\text {c }}$, Bastiaan Van Diedenhoven ${ }^{\text {d }}$, Kirk Knobelspiesse ${ }^{\text {a }}$, \\ Chris Hostetler ${ }^{\mathrm{e}}$, Rich Ferrare ${ }^{\mathrm{e}}$, Sharon Burton ${ }^{\mathrm{e}}$, John Hair ${ }^{\mathrm{e}}$, Michael D. Obland ${ }^{\mathrm{e}}$, Raymond Rogers ${ }^{\mathrm{e}}$ \\ a NASA Postdoctoral Program Fellow, NASA Goddard Institute for Space Studies, New York, NY, USA \\ b NASA Goddard Institute for Space Studies, New York, NY, USA \\ c Columbia University, Department of Applied Physics and Applied Mathematics, New York, NY, USA \\ d Columbia University, Center for Climate System Research, New York, USA \\ e NASA Langley Research Center, Hampton, VA, USA
}

\section{A R T I C L E I N F O}

\section{Article history:}

Received 24 September 2011

Received in revised form 10 February 2012

Accepted 17 February 2012

Available online 22 March 2012

\section{Keywords:}

Remote sensing

Polarization

Sunglint

Oil spill

Cirrus

Thin-film interference

\begin{abstract}
A B S T R A C T
In 2010, the Goddard Institute for Space Studies (GISS) Research Scanning Polarimeter (RSP) performed several aerial surveys over the region affected by the oil spill caused by the explosion of the Deepwater Horizon offshore platform. The instrument was deployed on the NASA Langley B200 aircraft together with the High Spectral Resolution Lidar (HSRL), which provides information on the distribution of the aerosol layers beneath the aircraft, including an accurate estimate of aerosol optical depth.

This work illustrates the merits of polarization measurements in detecting variations of ocean surface properties linked to the presence of an oil slick. In particular, we make use of the degree of linear polarization in the glint region, which is severely affected by variations in the refractive index but insensitive to the waviness of the water surface. Alterations in the surface optical properties are therefore expected to directly affect the polarization response of the RSP channel at $2264 \mathrm{~nm}$, where both molecular and aerosol scattering are negligible and virtually all of the observed signal is generated via Fresnel reflection at the surface. The glint profile at this wavelength is fitted with a model which can optimally estimate refractive index, wind speed and direction, together with aircraft attitude variations affecting the viewing geometry. The retrieved refractive index markedly increases over oil-contaminated waters, while the apparent wind speed is significantly lower than in adjacent uncontaminated areas, suggesting that the slick dampens high-frequency components of the ocean wave spectrum.

The constraint on surface reflectance provided by the short-wave infrared channels is a cornerstone of established procedures to retrieve atmospheric aerosol microphysical parameters based on the inversion of the RSP multispectral measurements. This retrieval, which benefits from the ancillary information provided by the HSRL, was in this specific case hampered by prohibitive variability in atmospheric conditions (very inhomogeneous aerosol distribution and cloud cover). Although the results presented for the surface are essentially unaffected, we discuss the results obtained by typing algorithms in sorting the complex mix of aerosol types, and show evidence of oriented ice in cirrus clouds present in the area. In this context, polarization measurements at $1880 \mathrm{~nm}$ were used to infer ice habit and cirrus optical depth, which was found in the subvisual/threshold-visible regime, confirming the utility of the aforementioned RSP channel for the remote sensing of even thin cold clouds.
\end{abstract}

(c) 2012 Elsevier Inc. All rights reserved.

\section{Introduction}

On 20 April, 2010, the Deepwater Horizon offshore platform $\left(28^{\circ} 44^{\prime} 12^{\prime \prime} \mathrm{N}, 88^{\circ} 23^{\prime} 13^{\prime \prime} \mathrm{W}\right)$ catastrophically exploded, killing 11 crew members and initiating an unprecedented leakage of "Louisiana sweet" crude oil that continued until the well was successfully

\footnotetext{
* Corresponding author. Tel.: + 12126785643.

E-mail address: mottaviani@giss.nasa.gov (M. Ottaviani).
}

capped on 15 July and declared "effectively dead" on 19 September. The National Incident Command Flow Rate Technical Group estimated that during this time 4.93 million barrels of oil were released from the well, with impacts on the surrounding ecosystem that are still largely unknown (Oil Budget Calculator Science and Engineering Team, 2010). This tragic event has once again alerted the global community to the importance of monitoring oil spill dynamics, which has been the subject of a number of studies mostly based on the Synthetic Aperture Radar (SAR) technique (Brekke \& Solberg, 2005; Nunziata et al., 2008). The SAR measurements have the advantage of being 
unaffected by the weather and can operate at nighttime, but require specification of the wind vector at the surface. In the visible range of the electromagnetic spectrum, oil spills in marine environments are difficult to detect by passive airborne and satellite remote sensors (Brekke \& Solberg, 2005; Goodman, 1994) because the oil only partially darkens the already dark ocean surface. Only under viewing conditions affected by specular reflection of solar radiation, often referred to as "sunglint", oil slicks can appear in stark contrast (see also Fig. 4). Sunglint has long been regarded as a challenge in remote sensing, since it masks the quantities of interest to the ocean color community with an overwhelmingly larger signal capable of saturating most of the instruments. Incidentally, data obtained from the Airborne Visible/Infrared Imaging Spectrometer (AVIRIS) on the same day as the data presented in this work, were discarded because of sunglint contamination (Clark et al., 2010). The extent of the sunglint "patch" is governed by the wave slope distribution, commonly modeled as a linear function of windspeed $w$ as proposed by Cox and Munk (1954, 1956). There is a small and often neglected dependence on wind direction, and the first-order result is a Gaussian distribution of wave slopes with a variance $\sigma^{2}=0.5 \times(0.003+0.00512 \times w)$. The intensity depends on the relative viewing geometry and the index of refraction of the underlying medium.

Expected physical effects of the oil include both a damping of the smaller-scale waves, due to the higher viscosity of oil with respect to water, and an increase in the surface refractive index. Both these factors lead to a higher peak intensity of the glint, because a narrower wave slope distribution reduces the angular extent of the reflection cone and higher refractive index implies higher reflectivity. Measurements
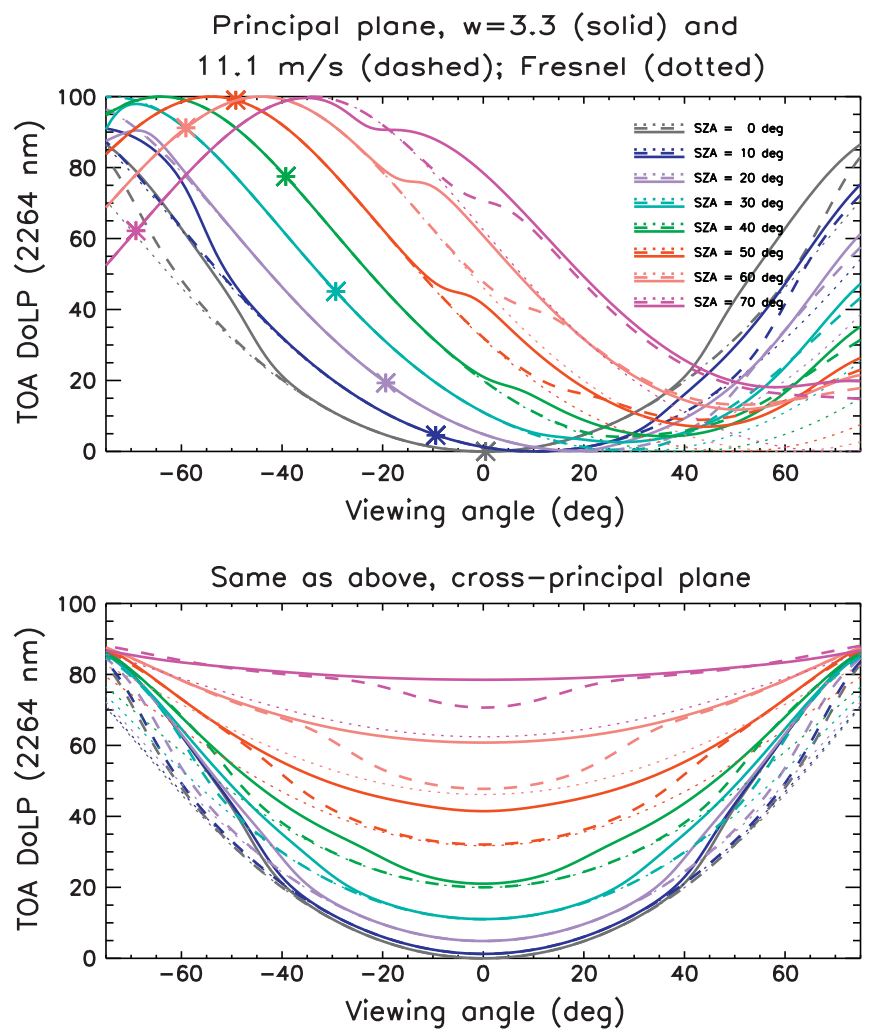

Fig. 1. Degree of Linear Polarization (DoLP) for different values of wind speeds (solid and dashed lines) and solar zenith angles (different colors) at $2264 \mathrm{~nm}$. The observations are simulated at the top of the atmosphere along the principal plane (top panel) and at a Sun-sensor relative azimuth equal to $90^{\circ}$ (bottom panel). The dotted lines represent the DoLP predicted by the Fresnel equations, and star symbols in the top plot mark the direction of specular reflection. These results validate the claim that the DoLP in the glint region is independent of the wind speed and is that predicted by the Fresnel relations. in atmospheric windows in the Short-Wave InfraRed (SWIR) range, where virtually all of the observed signal is generated by the surface, readily show these effects.

The Degree of Linear Polarization (DoLP) is defined as the fraction of the total reflectance which is linearly polarized. Sunglint is one of the most polarizing natural phenomena (Ottaviani et al., 2008c), and exhibits a DoLP which overwhelms that of any diffuse component. For measurements taken with a very narrow Instantaneous Field of View (IFOV), the DoLP within the glint region is unaffected by surface roughness and is determined exclusively by the Fresnel equations (Born \& Wolf, 1999). This perhaps counterintuitive concept is mathematically understood considering that the dependence of both the total and polarized reflectance on the wave slope distribution disappears upon taking their ratio. Physically, it is explained by considering that a nearly monodirectional viewing direction automatically determines the one tilt angle at the surface required to specularly reflect the incident beam into the detector's field of view (Ottaviani et al., 2008a). The $0.8^{\circ}$ IFOV of the NASA GISS Research Scanning Polarimeter (RSP, see Section 2) fulfills this condition. From typical airborne survey altitudes, its footprint at the surface (in the order of $100 \mathrm{~m}$ ) includes a number of wave facets large enough to sample the whole distribution of slopes. Among these, the slopes at the "right" angle for specular reflection, and responsible for the observed DoLP, belong to an angular range as narrow as the IFOV.

Because of the sensitivity to refractive index, DoLP measurements in the SWIR domain can therefore be very useful for oil slick detection provided appropriate observation geometries are used.

The paper proceeds with a sensitivity analysis which demonstrates, using Radiative Transfer (RT) simulations, that the DoLP in the glint region is not affected by surface waviness and is largely independent of the aerosol load, followed by a description of the theoretical basis for the method employed in the inversion of the photopolarimetric measurements collected by the RSP. Section 3 is divided into three subsections: the first discusses the results of the inversion leading to the detection of an altered ocean surface during the surveys over the Deepwater Horizon spill. A search for a complete set of aerosol descriptive parameters can be run within the implemented scheme, but prohibitive environmental conditions (mainly high aerosol spatial variability and uncharacterized and variable cirrus contamination above the aircraft) spoiled this possibility. The second and third subsections support these claims by building a context for the atmospheric conditions and presenting retrievals of the properties of a particular cirrus cloud that showed evidence of oriented ice crystals. Conclusions regarding the use of multi-angle polarization measurements to characterize the presence of oil are presented in Section 4.

\section{Methods}

\subsection{Sensitivity study}

We first confirm via RT simulations that the DoLP in the glint region is not affected by surface roughness. We employ a Doubling-Adding code (De Haan et al., 1987; Hansen \& Travis, 1974) which has the option to use a rough ocean surface (Cox \& Munk, 1954; Cox \& Munk, 1956) as the bottom boundary condition. It also includes a full treatment of multiple scattering processes, essential for accurate simulations in presence of aerosols (Ottaviani et al., 2008b).

In Fig. 1, different colors represent the DoLP computed at $2264 \mathrm{~nm}$ for different values of the Solar Zenith Angle (SZA), for a purely Rayleigh scattering atmosphere without gaseous absorption. The simulations in the top panel pertain to the principal plane of reflection, where sunglint is maximized at all viewing angles. For each SZA, the surface is modeled with a light wind ( $w=3.3 \mathrm{~m} / \mathrm{s}$, corresponding to a Cox-Munk variance $\sigma^{2}=0.01$, solid curves) and with a strong wind ( $w=11.1 \mathrm{~m} / \mathrm{s}$ or $\sigma^{2}=0.03$, dashed curves). The same plot also includes (dotted lines) the theoretical values of the DoLP computed 

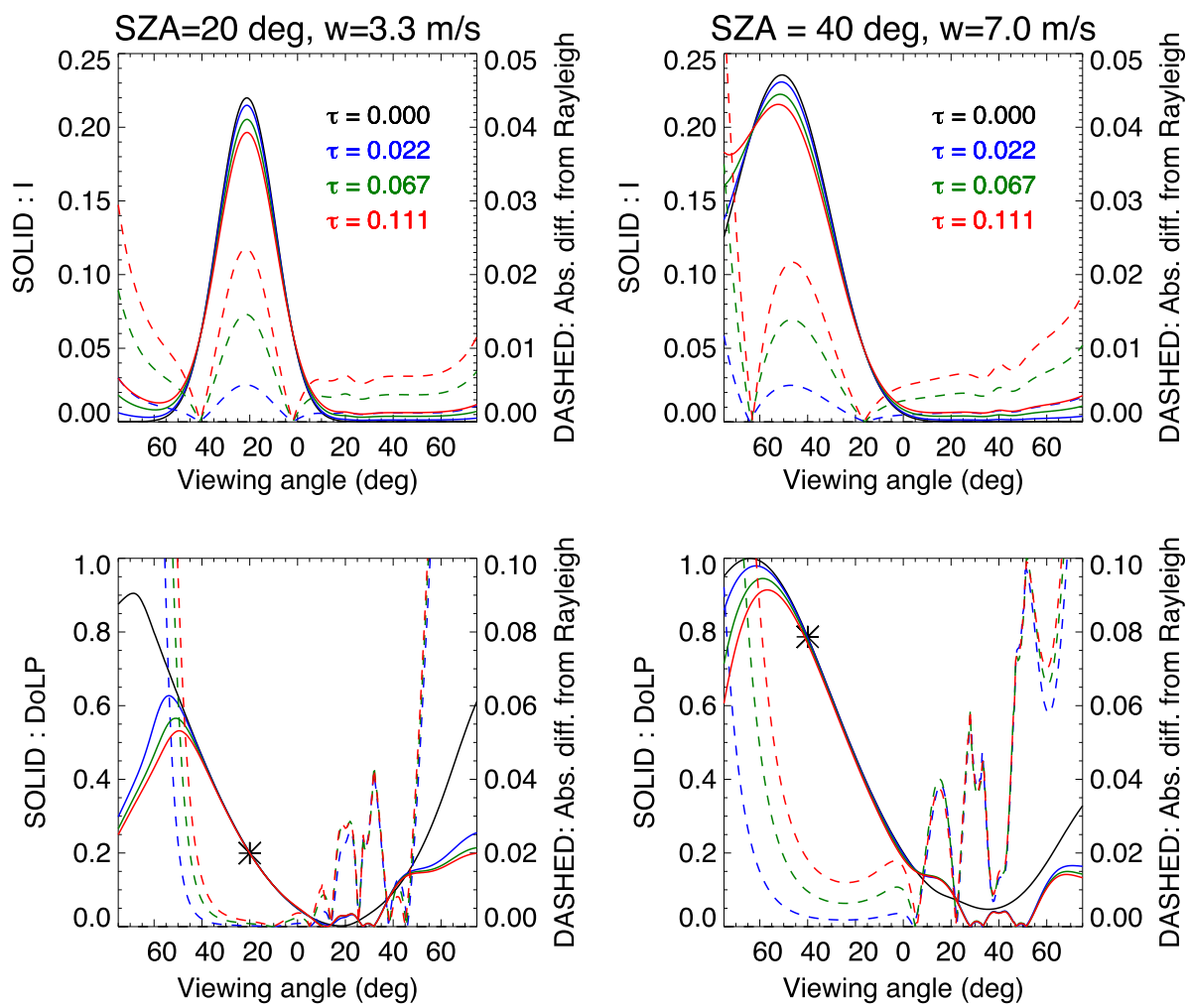

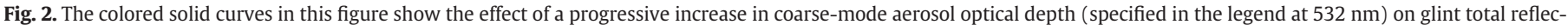

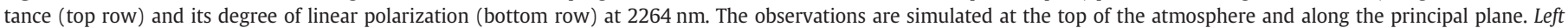

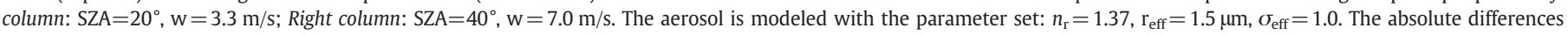

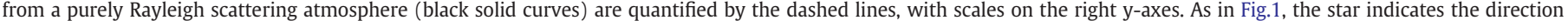
of specular reflection.

from the Fresnel equations for specular reflection. For ease of reference, all curves are simulated at the Top Of the Atmosphere (TOA) since they do not appreciably vary above typical RSP flight altitudes ( $\sim 9 \mathrm{~km}$, i.e. above most of the atmospheric scattering).

For each SZA, the curves for both wind speeds overlap with the corresponding Fresnel DoLP in a range of viewing angles whose midpoint is roughly the direction of specular reflection (marked with a star symbol). This angular range identifies the glint region. The curves depart from each other at the edge of the glint, where the strong polarization introduced by the sunglint decays and becomes comparable to the polarization effects introduced by the diffuse skylight.

Light of any polarization state impinging on a surface at Brewster's angle ( $\sim 53^{\circ}$ for pure water in the visible part of the spectrum) is converted upon reflection to light that vibrates only in the direction perpendicular to the plane of incidence. This suppression of the parallel component implies that for this angle of incidence the DoLP of the reflected radiation equals $100 \%$. The viewing angle at which this condition is fulfilled obviously depends on the SZA, as clearly visible in the figure.

Although still governed by Fresnel reflection, the leftover sunglint reflectance in the backscattering half-plane is dim compared to any other source of polarization (Rayleigh scattering in the case of Fig. 1). For example, the DoLP predicted by the Fresnel formulae is zero at exact backscatter, given the equal reflectivity of the perpendicular and parallel components at normal incidence. However, when either the Sun or the sensor are far from zenith, steeper slopes are required to redirect specular reflection into the field of view, and slopes larger than $25^{\circ}$ are rarely occurring (Cox \& Munk, 1956). While strong winds can still originate a few facets with extreme slopes, on a calm ocean this probability plummets, explaining the larger overlap between the predicted Fresnel reflectance in the high wind case compared to the low wind case.
Off principal plane, the sunglint reflectance dominates over a smaller range of viewing angles, apart from the trivial case of $\mathrm{SZA}=0^{\circ}$ for which there is no azimuthal dependence. The assumption that the DoLP is independent of the surface roughness holds well for SZAs up to $35^{\circ}$, or $55^{\circ}$ if the wind speed is significant (Fig. 1, bottom panel).

To mimic a more realistic situation, the same calculations were repeated for an atmosphere where the Planetary Boundary Layer (PBL), here set to an altitude of $1 \mathrm{~km}$, was injected with aerosols typical of a marine environment. The presence of non-absorbing, salt-like particles was modeled with a log-normal distribution (Hansen \& Travis, 1974) characterized by an effective radius $r_{\text {eff }}=1.5 \mu \mathrm{m}$ and an effective variance $\sigma_{\text {eff }}=1.0$. The real part of the refractive index was set to 1.37 and the number density adjusted to give increasing optical depth up to a value of 0.11 at $532 \mathrm{~nm}(\sim 0.09$ at $2264 \mathrm{~nm})$. These microphysical parameters are translated into optical properties within the Doubling-Adding code according to the Lorenz-Mie theory (Mishchenko \& Travis, 2008). It is not important at this stage to detail effects due to fine-mode aerosols, since their contribution to scattering at $2264 \mathrm{~nm}$ is negligible (optical depth on the order of 0.001 ) as long as the loading is limited to reasonable amounts (Chowdhary et al., 2005).

Figure 2 collects the results of the computations, focusing on principal plane observations since flying close to this direction provides the best observations of sunglint (as shown in Fig. 1), and also maximizes the range of scattering angles probed by the RSP instrument. Two pairs of significantly different SZA $\left(20^{\circ}\right.$ and $\left.40^{\circ}\right)$ and windspeed ( 3.3 and $7.0 \mathrm{~m} / \mathrm{s}$ ), are arranged into two columns to allow the comparison between the variability of the total reflectance versus that of the DoLP, as the viewing angle points into, or outside of, the glint region. This variability is quantified by the dashed lines corresponding to the DoLP absolute difference from the Rayleigh case (black solid curves), which serves as convenient reference (in the glint region 

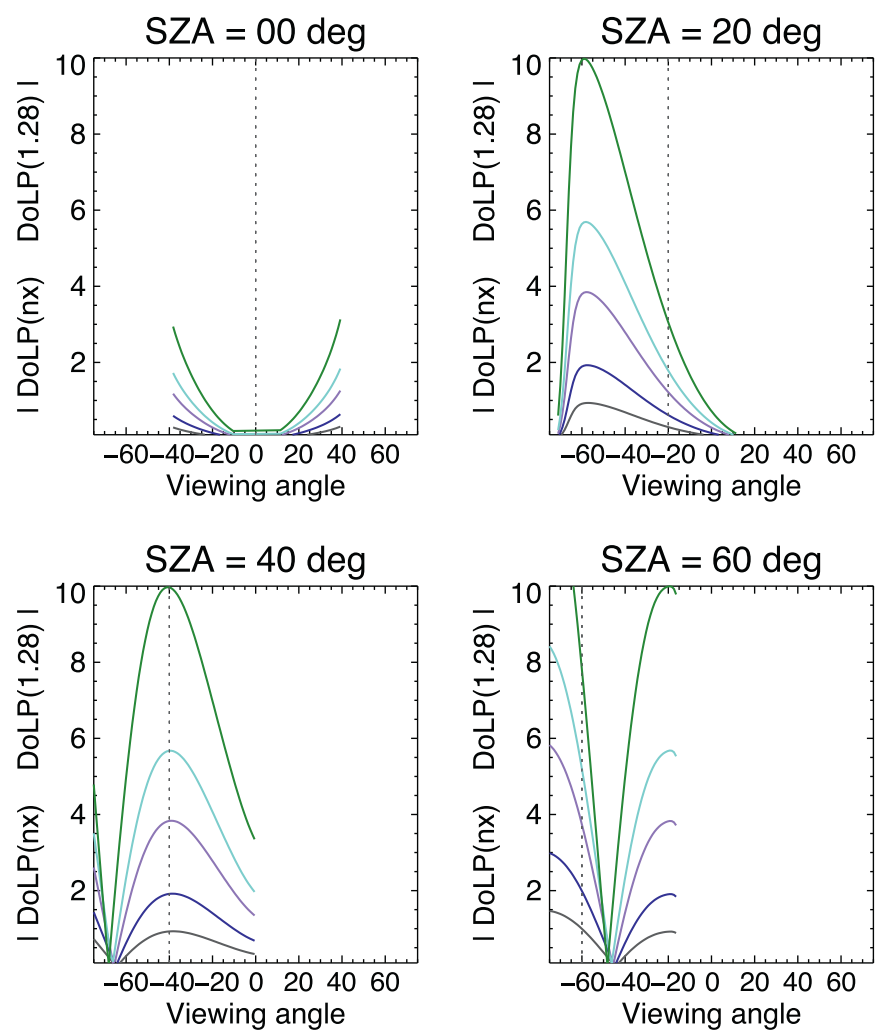

Fig. 3. Absolute value of the change in the Degree of Linear Polarization at the TOA when the refractive index of water at $2264 \mathrm{~nm}$ changes from 1.28 to 1.30 (gray), 1.32 (blue), 1.36 (purple), 1.40 (cyan) and 1.50 (green). The different panels correspond each to a different SZA, and all pertain to principal plane observations. The vertical dotted lines indicate the direction of specular reflection.

the difference between the DoLP of a Rayleigh atmosphere and that predicted by the Fresnel model is less than $0.05 \%$ ). Around the backscatter direction (positive angles), the glint contribution decreases and the signature of coarse-mode aerosol scattering is apparent. At negative angles, near the center of the glint, the departures are appreciable for the total reflectance (over $10 \%$ in relative terms for the largest load), while it is restricted for the DoLP to very small values even at very significant aerosol optical depths. From the discussion following Fig. 1, it is clear that the larger departures in the bottom right panel are attributable to the higher SZA $\left(40^{\circ}\right)$ rather than to the increased windspeed $(7.7 \mathrm{~m} / \mathrm{s})$. Indeed, a larger SZA implies a longer path in the atmosphere which augments the probability for the aerosol layer to scatter the direct beam. Even if coarse-mode maritime aerosols rarely exhibit significant absorption, test cases were also run by progressively increasing the imaginary part of the refractive index up to 0.02 for the aerosol amount corresponding to the largest load, for the same viewing geometry as in the left column of Fig. 2. Very similar ranges were found for the departures ( $\sim 10 \%$ for the total reflectance and $<1 \%$ for the DoLP).

For the reader interested in more investigations on the DoLP relative to the atmosphere-ocean system, we point to the works of Stam et al. (1999) and Shaw (1999, 2001).

Fig. 3 summarizes the sensitivity of the previous curves to a change in refractive index of the underlying medium. Several studies exist in literature about the effect of certain types of crude oil on the refractive index of pure water at visible wavelengths, indicating that most emulsions can easily exhibit values up to 1.5 or even higher (Król et al., 2006; Otremba, 2000; Otremba \& Piskozub, 2003). Unfortunately, data in the SWIR are scarce and somewhat dated, but seem to indicate that also in this spectral region a similar increase can be expected (Al'perovich et al., 1978; den Boer et al., 1995). A possible reason for the lack of data in the SWIR is the difficulty in resolving oscillations of the real part of the refractive index in regions with strong absorption features (as predicted by the Kramers-Kronig dispersion relations), and reflectance spectra of the Deepwater oil indeed show alkane absorption in the SWIR region (Clark et al., 2010). We therefore chose to examine the differences in DoLP caused by gradual increments in refractive index relative to that of pure water, here taken as 1.2815 at $2264 \mathrm{~nm}$ as recommended by the International Association for the Properties of Water and Steam (IAPWS) (Harvey et al., 1998).

Each panel in Fig. 3 is for a value of SZA, and the vertical scale is the absolute value of the absolute change in observed DoLP with respect to that expected for pure water. For clarity, each curve is plotted only in the range of viewing angles corresponding to the relative sunglint region. Following Fig. 1, this region was determined as that for which both curves are within 5\% of the theoretical Fresnel curve.

Within the glint region, a change in the refractive index causes very significant changes in the DoLP. In most situations, a variation from 1.28 to 1.30 (only $2 \%$, gray curves) is sufficient to produce a change in DoLP well above the detection capabilities of an instrument such as the RSP whose polarimetric accuracy is $0.2 \%$. Exceptions occur (i) in conditions of overhead Sun, which generates very little polarization (exactly zero at backscatter), and (ii) at the Brewster's angle, where the suppression of the component of light parallel to the plane of reflection creates $100 \%$ polarization. The Brewster's angle shifts from $52^{\circ}$ to $56.3^{\circ}$ over this range of refractive indices, and close to this interval the DoLP difference plummets to very small values. Operationally, observations along the principal plane with SZAs between $20^{\circ}$ and $40^{\circ}$ are therefore most convenient, because they guarantee both that sufficient polarization is generated to detect its variations with high signal-to-noise ratio, and that the conditions for Brewster geometry are not met near the center of the glint region.

This brief excursus shows that the DOLP measured in the SWIR, preferably at moderate SZAs, is largely dominated by variations in surface refractive index.

\subsection{Instrumentation and research flights}

The RSP (Cairns et al., 1999) and the Langley airborne High Spectral Resolution Lidar (HSRL) (Hair et al., 2008; Rogers et al., 2009) were mounted on the B200 King Air aircraft based at NASA Langley Research Center, Hampton, VA. Flying these two instruments side-by-side is of high value since the HSRL provides profiles of aerosol layers below the aircraft. The vertical structure of the scene context can then be used to constrain the RSP observations; this synergistic exploitation for the retrieval of aerosol descriptive parameters has been the subject of recent studies (Knobelspiesse et al., 2011).

Surveys over the region affected by the oil spill began in May 2010, exploiting transit flights to California where the B200 participated in the Research at the Nexus of Air Quality and Climate Change (CalNex) campaign, a joint effort involving the California Air Resources Board (CARB), the National Oceanic and Atmospheric Administration (NOAA) and the California Energy Commission (CEC). Other flights over the same area occurred on 9 and 10 July, and 28 September. Concurrently with lidar-dedicated science objectives, the flight patterns were designed with long, straight segments covering regions of shallow waters, open-ocean clean waters, and waters contaminated by the spill following the predictions of transport models.

The instantaneous field of view (14 mrad) of the RSP is continuously scanned within $\pm 60^{\circ}$ from nadir by a polarization-insensitive scan mirror system, leading to approximately 150 viewing angles for each scan. Scanning along-track, the same scene is therefore viewed from multiple angles in successive scans. The optical assembly 

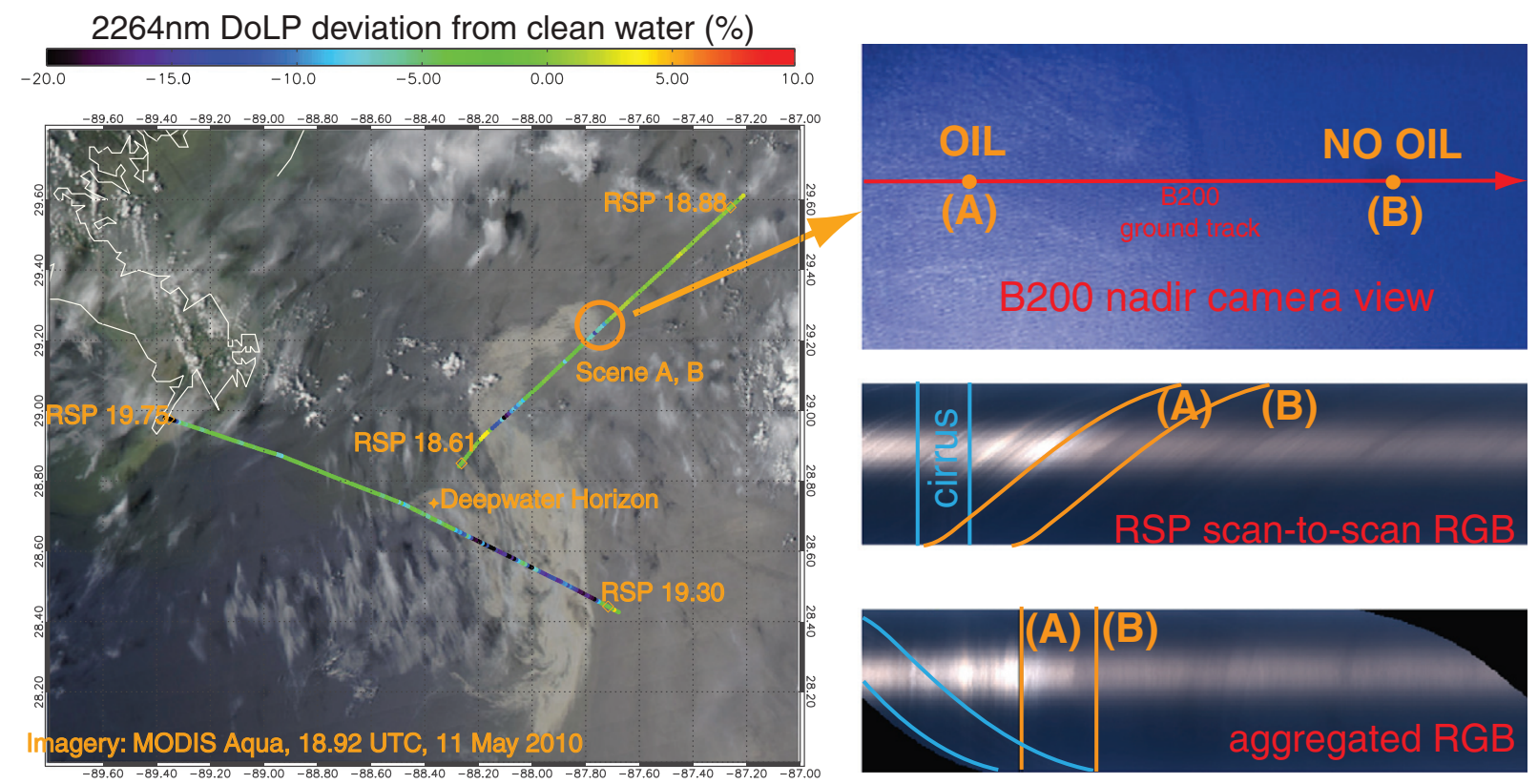

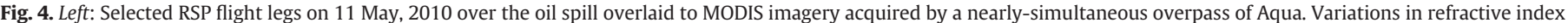

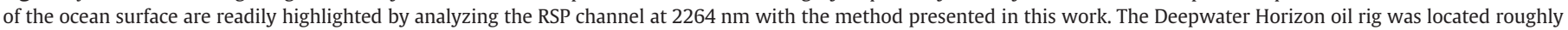

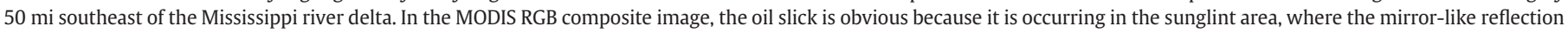

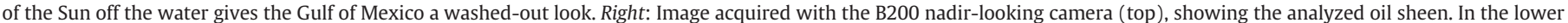

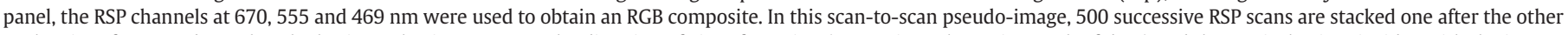

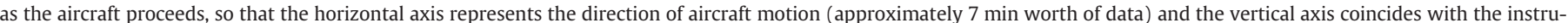

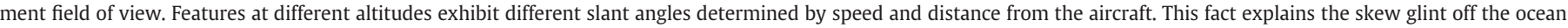

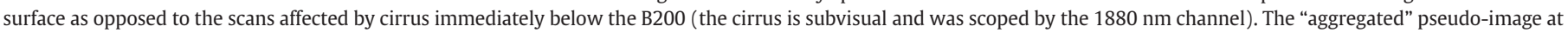

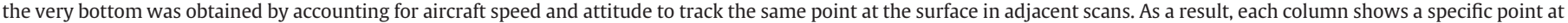
the surface seen from different angles. The two analyzed scenes are marked with (A) and (B).

consists of three pairs of boresighted refractive relay telescopes, collecting measurements in 9 channels overall from the visible to the SWIR portion of the spectrum $(410,469,55,670,864,960,1594$, 1880 and $2264 \mathrm{~nm}$ ). The paired design is required to determine the I, Q and U Stokes parameters (Hansen \& Travis, 1974) of light from the simultaneous measurement of the two orthogonal polarization states at $0^{\circ}$ and $90^{\circ}$ to the meridional plane of the instrument (first telescope), and the equivalent intensities at $45^{\circ}$ and $135^{\circ}$ (second telescope). The orthogonal polarization states of the incoming light are spatially separated by a Wollaston prism and measured simultaneously.

The reflectances measured by the RSP are related to the first three components of the Stokes vector I, Q and U, as follows:

$$
\begin{aligned}
& \mathrm{R}_{\mathrm{I}}=\frac{\pi r_{0}^{2}}{F_{0} \mu_{0}} \mathrm{I} \\
& \mathrm{R}_{\mathrm{Q}}=\frac{\pi r_{0}^{2}}{F_{0} \mu_{0}} \mathrm{Q} \\
& \mathrm{R}_{\mathrm{U}}=\frac{\pi r_{0}^{2}}{F_{0} \mu_{0}} \mathrm{U}
\end{aligned}
$$

where $F_{0}$ is the annual average extraterrestrial irradiance $\left(\mathrm{W} \mathrm{m}{ }^{-2}\right)$, $r_{0}$ is the solar distance in $\mathrm{AU}$, and $\mu_{0}$ is the cosine of the SZA. The high absolute accuracy of polarization measurements $(0.2 \%$ for DoLP), achieved with an internal relative calibration performed during each scan, is a fundamental characteristic of the RSP.

Along-track scanning relies on the same feature being observed in consecutive scans as the aircraft proceeds. The simplest analysis of RSP data in fact requires identifying the same feature in consecutive scans to form the angular behavior of its reflectance (see Fig. 4). For this reason, the effective use of data is deeply affected by variations in aircraft attitude. A relatively small aircraft like the B200 operates with a positive pitch (the angle of attack) typically in the $2.5^{\circ}-4^{\circ}$ range depending on speed. Pitch is the largest source of error when collecting multi-angle measurements, since it directly impacts the viewing zenith angle, but for the same reason it is easily corrected for provided a reliable Inertial Measurement Unit (IMU) is available. Yaw can also be easily accounted for since it only modifies the SunRSP relative azimuth, but it prevents large fore and aft angles from scanning along-track and therefore causes a feature to not be seen at all available angles. If not limited to small values (typically between $1.5^{\circ}$ and $-1.5^{\circ}$ ), roll presents the greatest challenge for correction since it simultaneously influences both zenith and azimuth angles, leading to continuous off-track excursions.

Optimal RSP data are collected in flight legs oriented close to the principal plane (Sun-RSP relative azimuth equal to $0^{\circ}$ or $180^{\circ}$ ), where the range of scattering angles collected by the instrument in successive scans is maximized. The present analysis benefits from this general requirement since the sunglint signal is strongest in the principal plane.

Specific routines have been implemented for data mining, highlighting RSP data segments where both aircraft attitude parameters and orientation relative to principal plane are contained within desired tolerance values.

\subsection{Algorithm}

As a first step, the reflectance measured at $2264 \mathrm{~nm}$ was corrected for gaseous absorption. Water vapor amounts to approximately $0.33 \%$ of the mass of the atmosphere, and peak values near the surface can reach $\sim 4 \%$ of the mass of air. At $10 \mathrm{~km}$ this value is $\sim 0.04 \%$, so that for typical B200 altitudes around 8-9 km, practically all water vapor is found below the aircraft. In this case, the ratio between the signal in a channel subject to water vapor absorption and one in a window 
can be used over bright areas to retrieve the precipitable amount (Gao \& Kaufman, 2003). The RSP offers this possibility through the reflectances measured at $960 \mathrm{~nm}$ and $864 \mathrm{~nm}$ which were used to calculate:

$\frac{\mathrm{R}_{\mathrm{I}}(960)}{\mathrm{R}_{\mathrm{I}}(864)}=\exp \left[-\alpha\left(a_{m} W_{v}\right)^{\beta}\right]$

where $a_{m}$ is the airmass, $W_{v}$ is the water vapor column (in precipitable $\mathrm{cm}$ ), and $\alpha=0.31607$ and $\beta=0.595575$ are instrument-specific constants (Halthore et al., 1997). The optical depth at $2264 \mathrm{~nm}$ associated to the retrieved column amount was then evaluated based on look-up tables previously compiled using solar spectrally weighted values with correlated- $k$ distributions (Cairns et al., 2003; Lacis \& Oinas, 1991; Rothman et al., 2003). Because water vapor absorption in this band is dominated by the continuum, this procedure defines an effective absorption optical depth $\tau_{\text {abs }}$ below the aircraft and a transmittance $T_{1}$ linked to strong line absorption by methane and the portion of water vapor located above the aircraft. The two-pass transmittance is therefore:

$T\left(\mu_{\mathrm{v}}, \mu_{0}, W_{v}\right)=T_{1}\left(\mu_{0}, W_{v}\right) \exp \left[-\tau_{\mathrm{abs}}\left(\frac{1}{\mu_{0}}+\frac{1}{\mu_{\mathrm{v}}}\right)\right]$.

The absorption optical depth is allowed to depend on the cosine of the SZA, $\mu_{0}$, to improve the fit to the exact calculations, even though the variation of $\tau_{\mathrm{abs}}$ with SZA is less than 0.006 for solar zenith varying from $65^{\circ}$ to $0^{\circ}$ for $5 \mathrm{~cm}$ of precipitable water vapor. In the analyzed scenes, retrieved water vapor amounts were close to $3.85 \mathrm{~cm}$ leading to a two-pass transmittance at $2264 \mathrm{~nm}$ of $\sim 86 \%$ for angles of observation close to nadir. The glint region was selected by thresholding the total reflectance signal at $2264 \mathrm{~nm}$, and the DoLP obtained from the ratio of the polarized to the total reflectance.

In the main body of the algorithm, the output of the DoublingAdding model is optimized by means of an Interactive Data Language (IDL) inversion routine (MPFIT) of the Levenberg-Marquardt kind (Moré, 1978), translated from the FORTRAN package MINPACK and offered publicly by Markwardt (2009). This particular implementation was found useful for its robustness, and because it is very flexible in constraining the optimization as explained below.

An inversion problem is most often based on the minimization of a cost function $\Phi(\mathbf{x})$ :

$\Phi(\mathbf{x})=\left\|[\mathbf{Y}-\mathbf{G}(\mathbf{x})] \mathbf{C}_{\mathrm{Y}}^{-1}[\mathbf{Y}-\mathbf{G}(\mathbf{x})]^{T}\right\|^{2}$

which describes the misfit between a model function $\mathbf{G}(\mathbf{x})$, of the set of parameters forming the state vector $\mathbf{x}$, and the vector of observations $\mathbf{Y}$. A coherent application of the method requires that the measurement errors be specified, for the role of the inverse of covariance matrix $\mathbf{C}_{Y}$ is to weight the observations according to their uncertainties.

Minimizing this function, which for non-linear problems becomes an iterative procedure, involves first the use of derivatives (Jacobians) to realize the local topography of the cost function, and then some technique to determine the length of the step attempted in the direction of an alleged minimum. The most popular methods are the steepest descent and the Newton method, which perform best in different situations: the former consistently proceeds with small steps in the direction of the largest gradient, while the latter converges quadratically in the vicinity of minimum based on the information on concavity contained in the second derivative (or Hessian) of the function. The Levenberg-Marquardt algorithm combines these two methods and can significantly improve the search by alternating "long steps" in regions of low concavity and quadratic convergence near a minimum.

Inverse methods can provide optimal solutions (in a statistical sense), but it is generally very hard to find this solution when estimating many parameters at once (Rodgers, 2000). In regions of rapid variations in reflectance, as is the case of sunglint, the search space presents several minima because unconstrained pitch and yaw can accommodate variations in refractive index or other parameters. To mitigate such uniqueness problems and ensure convergence to a physically meaningful solution, choosing the variables appropriate to the available information content is as important as starting the iterations with a sensible choice of the initial values. Full control on these parameters and improved stability in iterations involving values close to their bounds are advantageous features offered by MPFIT when exploring the sensitivity to aircraft attitude.

For the reasons listed above, a simultaneous fit is attempted for the DoLP in the glint region and the total reflectance, with the surface refractive index, pitch and yaw, and windspeed as free parameters. Although the windspeed does not affect the DoLP, it is useful to simultaneously fit the glint reflectance, since the angular position of its peak provides constraints on pitch and yaw offsets. Potential uncertainties due to wind direction are believed to be negligible since the retrieved wind speed is significantly smaller than the threshold ( $5 \mathrm{~m} / \mathrm{s}$ ) above which this effect starts manifesting its importance (Masuda, 1998).

\section{Results and discussion}

\subsection{Surface properties retrievals}

In the left side of Fig. 4, the percent difference of measured DoLP from that expected from clean water is color coded over a background image obtained by the MODIS instrument onboard the Aqua satellite at 18.92 UTC, and therefore very close in time to the B200 survey. Liquid water clouds and cirrus clouds are visible all around the region, but the oil slick emerges in stark contrast because of the sunglint, as anticipated in the Introduction section. The right side of Fig. 4 contains an image captured by the B200 nadir camera together with the portion of RSP data (RGB composite) containing the scans of interest.

The measured DoLP drops in regions of the ocean visibly affected by the oil spill, that exhibit higher refractive index. A selected portion of the data, corresponding to the area marked with the "Scene A, B" label, is plotted in Fig. 5. This section was chosen because it is closely aligned to the principal plane $\left(\sim 8^{\circ}\right.$ away from it) and will be further analyzed in the remainder of the paper. The effects of bright clouds below the aircraft are obvious in the correlations between the DoLP and peaks in the reflectances at $670 \mathrm{~nm}$ (top panel). The subvisual cirrus present under the aircraft at 18.74 UTC, as revealed by the $1880 \mathrm{~nm}$ channel (located within a strong water vapor absorption band), has negligible effects on the DoLP, as discussed in Section 3. In view of the previous discussion on the advantage of a straight and level attitude, pitch, yaw and roll stored from the IMU are overplotted in color; the scale on the y-axis for these parameters has units of degrees. As previously noted, a rather stable positive pitch (green curve) is expected from flight mechanics, and the RSP viewing zenith angles are corrected accordingly.

Sidewind conditions are responsible for the yaw, suggesting that tail- or headwind was likely encountered during the lower transect in Fig. 4 for which "crabbing" is minimal (not shown). Especially for angles close to nadir, features along the flight track are captured even in the presence of yaw, which is accounted for by choosing aircraft heading rather than track direction when calculating the Sun-RSP relative azimuth. After these corrections, there is a residual correlation between percent DoLP difference and roll. A further exploration of this correlation could help "cleaning up" the signal, but the effects of roll are clearly small compared to the effects of surface oil and water clouds.

The sparse cloud cover forbids a systematic translation of the glint reflectance measured along the flight track into absolute values for the refractive index, because of uncertainties in the illumination conditions. To gain more insight on the relationship between surface oil 


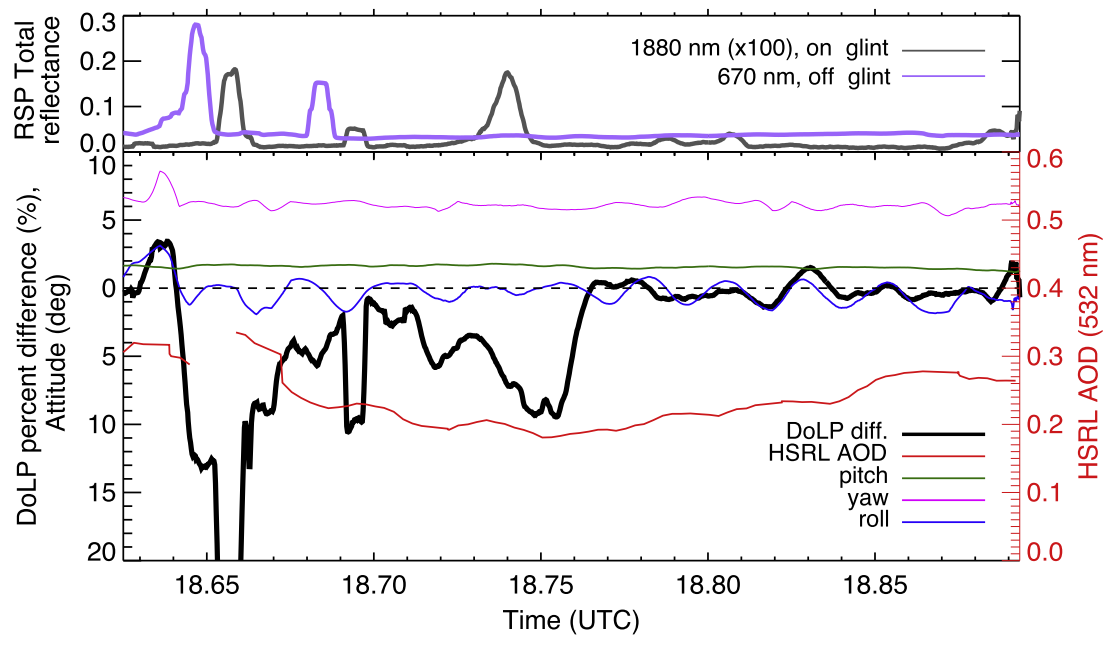

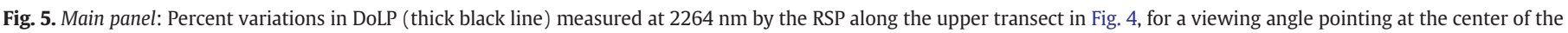

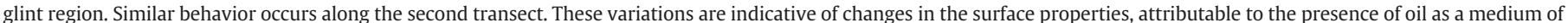

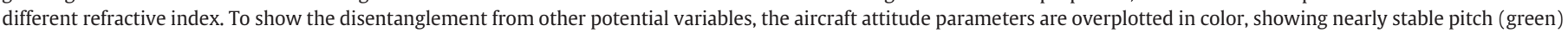

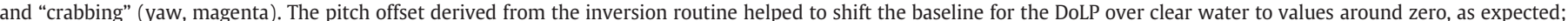

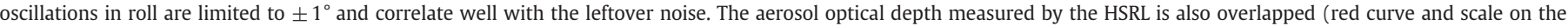

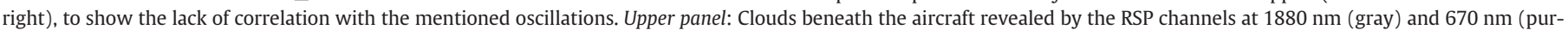

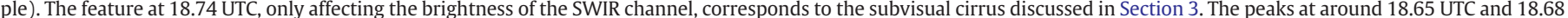

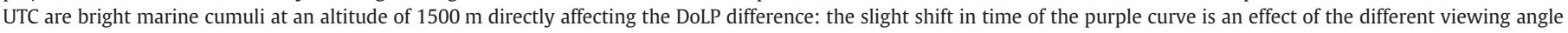
used to avoid glint contamination in the $670 \mathrm{~nm}$ channel.

and the variations in glint brightness apparent in the RSP images (Fig. 4, right), we limited the investigation to a small area at the edge of the sheen where we can assume that the cirrus cover above the aircraft, if present, provides a constant attenuation of the incoming sunlight. Note that it is sufficient for this assumption to hold over the range of RSP viewing angles needed to assemble the portion of the glint passed to the optimization routine.

The two analyzed scans are referred to as "Scene A" (18.75 UTC, affected by oil on the surface) and "Scene B" (18.76 UTC, over clear water), and are only about $45 \mathrm{~s}$ apart on either sides of the edge of the sheen. As a first step, the inversion procedure was run on Scene B allowing as free parameters the refractive index of the surface, the wind speed, and a scaling factor for the total reflectance. Since this same scaling factor is applied also to the polarized reflectance, it does not affect the DoLP. No offsets are allowed for yaw given the relative stability of aircraft heading along the transect, which defines an accurate Sun-RSP azimuth. Pitch is also stable, but we left it unconstrained to absorb the combined effect of systematic offsets and roll (see discussion at the end of Section 2). This way, the correction can be regarded as an effective pitch which anchors the model to the angular position of the maximum of the sunglint peak.

The results of the fitting are reported in Fig. 6, in which the most apparent feature is the twofold increase in glint brightness for scans over oil (right panels). The retrieved refractive index of the surface for Scene B is at the lowest limit of the allowed interval, which coincides with that of pure water at $2264 \mathrm{~nm}$ (1.28). The scaling factor for the total reflectance amounts to $0.92 \pm 0.01$, reasonable considering that the operator's notes report cirrus above (see Section 3 for a more thorough discussion). The pitch correction found is $1.20 \pm$ $0.05^{\circ}$. An average of the pitch offsets for adjacent scenes was accounted for when plotting the DoLP in Fig. 5, and it is noteworthy that this procedure helped shifting the signal to a baseline around zero over clear water.

The uncertainties listed above are a convenient byproduct of MPFIT and of any optimal estimation method. For fits of good quality as is the case here, a simple form of the error covariance matrix can be obtained by considering uncorrelated noise and equal weights for all data points in a signal. Errors were set to $7.5 \%$ for both DoLP and total reflectance, because the RSP polarimetric and calibration errors are dominated by the error sources associated with instabilities in aircraft attitude.

If the optimization is then run on Scene A (top two panels) with the scaling factor for reflectance kept fixed at 0.92 , the retrieved refractive index increases to $1.345 \pm 0.001$ while the windspeed decreases to $3.26 \pm 0.03 \mathrm{~m} / \mathrm{s}$ (the pitch offset is in this case $0.30 \pm 0.04^{\circ}$ ). To test the algorithm stability, the optimization was repeated by varying in sequence the parameters previously kept fixed. As expected, the scaling factor showed variability within the measurement error set for the reflectance, but the variations in refractive index and wind speed were negligible $(0.01$ and $0.01 \mathrm{~m} / \mathrm{s}$, respectively). This confirms that the search for the optimal wind speed is stable and not affected by the particular value of the scaling factor, and the determination of an absolute value for the refractive index should be feasible provided observational conditions more ideal than here are met along the track (minimized roll, absence of cirrus cover). The very good quality of the fitting and the magnitude of the differences between the two scenes, as large as $1.2 \mathrm{~m} / \mathrm{s}$ for windspeed and 0.07 in refractive index, seem to exclude the possibility that these variations are coincidental or caused by modeling errors.

The detection of a smaller apparent wind speed for scene A with respect to scene B is therefore an interesting result. It suggests that the presence of oil on the surface dampens at least part of the capillary waves, increasing the glint brightness as a consequence as does the simultaneous increase in refractive index. This behavior is in agreement with what reported in the original studies of Cox and Munk (Cox \& Munk, 1954; Cox \& Munk, 1956).

Finally we note that including coarse-mode particles in the modeling, with an optical depth consistent with HSRL measurements, improves the model fit at off-glint angles while not changing the values retrieved for wind speed and refractive index.

Whether the oil located in the area examined in this study is partly organized in a slick with a well-defined thickness remains to be established. This analysis is limited to the region at the edge of the slick where the thinning layer can break due to Langmuir circulation and oil droplet dynamics (Farmer \& Li, 1994; Lehr \& Simecek-Beatty, 2000; Thorpe, 2000). Also, the highly volatile Louisiana crude can 

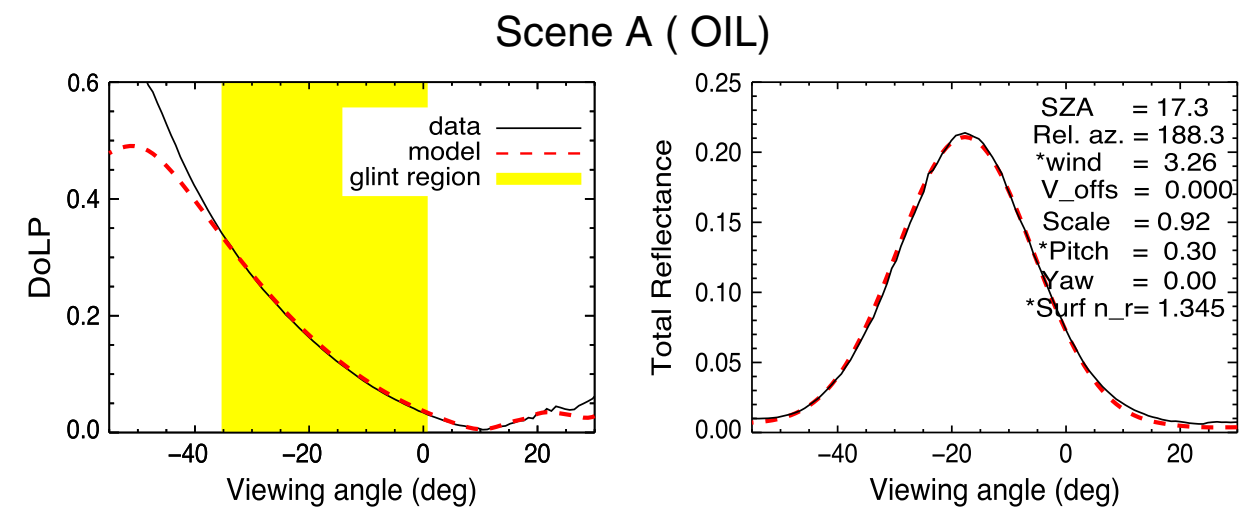

Scene B ( NO OIL)
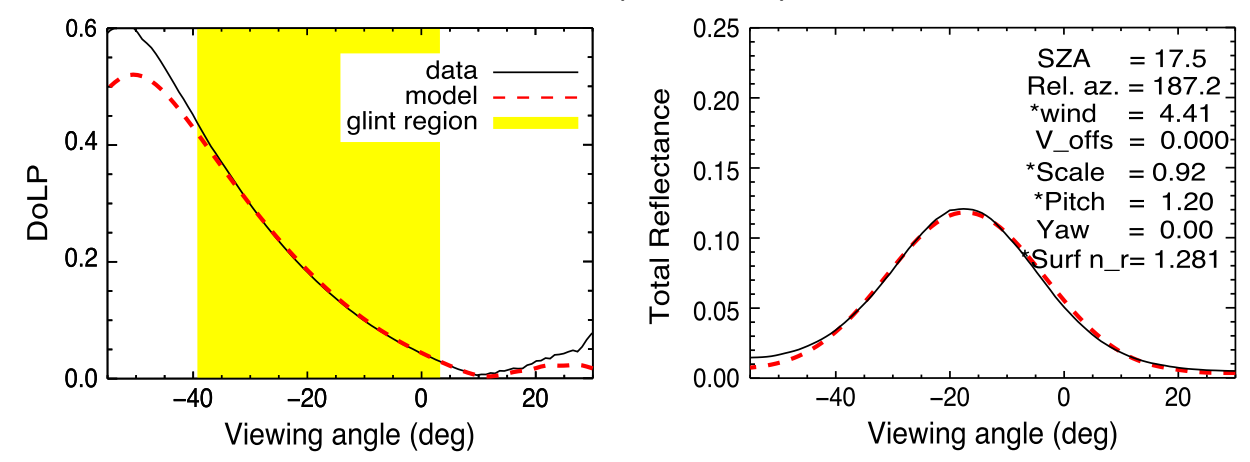

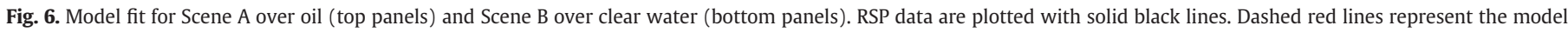

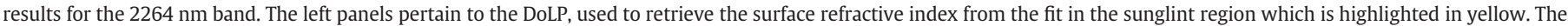

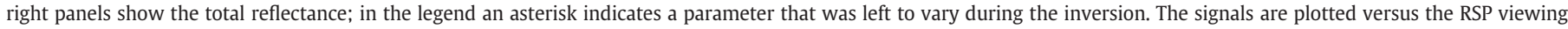

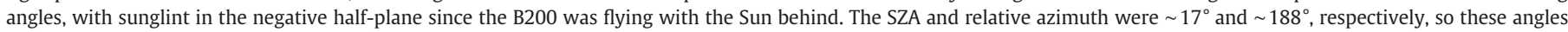

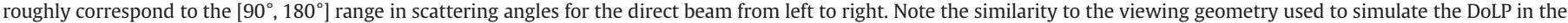
left column of Fig. 2.

lose up to half of its mass during the first days at sea and subsequent weathering supports in many cases a marked tendency of this oil to emulsify (Oil Budget Calculator Science and Engineering Team, 2010). In this respect, it has been shown by Clark et al. (2010) in laboratory measurements that the spectrum of the oil in the visible is not affected by oil thickness as much as it is affected by the oil-to-water ratio. Thicknesses up to a few microns, of a film of higher refractive index deposited on water, can be estimated from the color shift caused by the interference between the $\left(180^{\circ}\right.$ out-of-phase) electromagnetic waves reflected from the film first surface and the (in-phase) waves reflected from the second surface (Born \& Wolf, 1999). The multispectral capabilities of the RSP can in principle be used for this purpose and we have included in A an estimate of how interference affects visible color. However, the distance from the target needs to be optimized with respect to the IFOV to properly resolve such effects.

\subsection{Aerosol scenario}

In this section we discuss the high variability of the aerosol scenario characterizing the survey, exploiting among the rest an aerosol typing algorithm based on cluster analysis of the HSRL data products (Burton et al., 2012). The HSRL data from the transit flight on 10 May over the Carolinas onward to Alabama and Mississippi evidenced an elevated layer of dust, easily identified by its high depolarization values (up to 25\%). The analysis of back trajectories simulated with the HYSPLIT (Draxler \& Rolph, 2010) online tools is shown in Fig. 7 and points to a possible Asian origin for the airmass at these latitudes. Significant storms were indeed observed by the MODerate resolution Imaging Spectroradiometer (MODIS) in India and Pakistan in the beginning of May, and in Western China during the last week of April. Caution should be used however in linking the effects of the observations to such remote dust events, due to the uncertainty associated with back trajectories extending so far back in time.

Closer to the Gulf area the dust lessened, gradually mixing with a layer of radically different properties, specifically low depolarization, high extinction-to-backscatter (lidar) ratio, and high backscatter wavelength dependence. Both smoke and urban pollution can be responsible for such a behavior, and discriminating between the two is challenging. The ratio of depolarization ( $1064 \mathrm{~nm} / 532 \mathrm{~nm}$ ) can sometimes aid the distinction, but carries high uncertainty due to the low depolarization values.

A dusty mix with the same properties of that previously described was also encountered on 11 May over Texas, with the B200 on its way to California. Back trajectories initiated at an altitude of $4 \mathrm{~km}$ in proximity of the flight track show that this area was at the confluence of two airmasses: the one already ascribed to a possible long-range transport from Asia, and another with air which had been circulating for a few days around the Mexican plateaus with a good degree of vertical excursion, making it possible for these parcels to have carried particulates from lower altitudes.

A multitude of agricultural fires had been burning in several Mexican locations for about two weeks. Forward trajectories for three sample locations initiated at ground level indicate more or less constant transport of airmasses originating in the Yucatan peninsula along the eastern coast of Mexico into Texas, although the model does not account for pyroconvection caused by burning fires. On 1 May, there was significant transport directly into the Gulf. It seems safe at this point to assume the presence of some Mexican smoke, up to a couple of weeks old, at low elevations around the Deepwater 
NOAA HYSPLIT MODEL

Backward trajectories ending at 1800 UTC 11 May 10

GDAS Meteorological Data

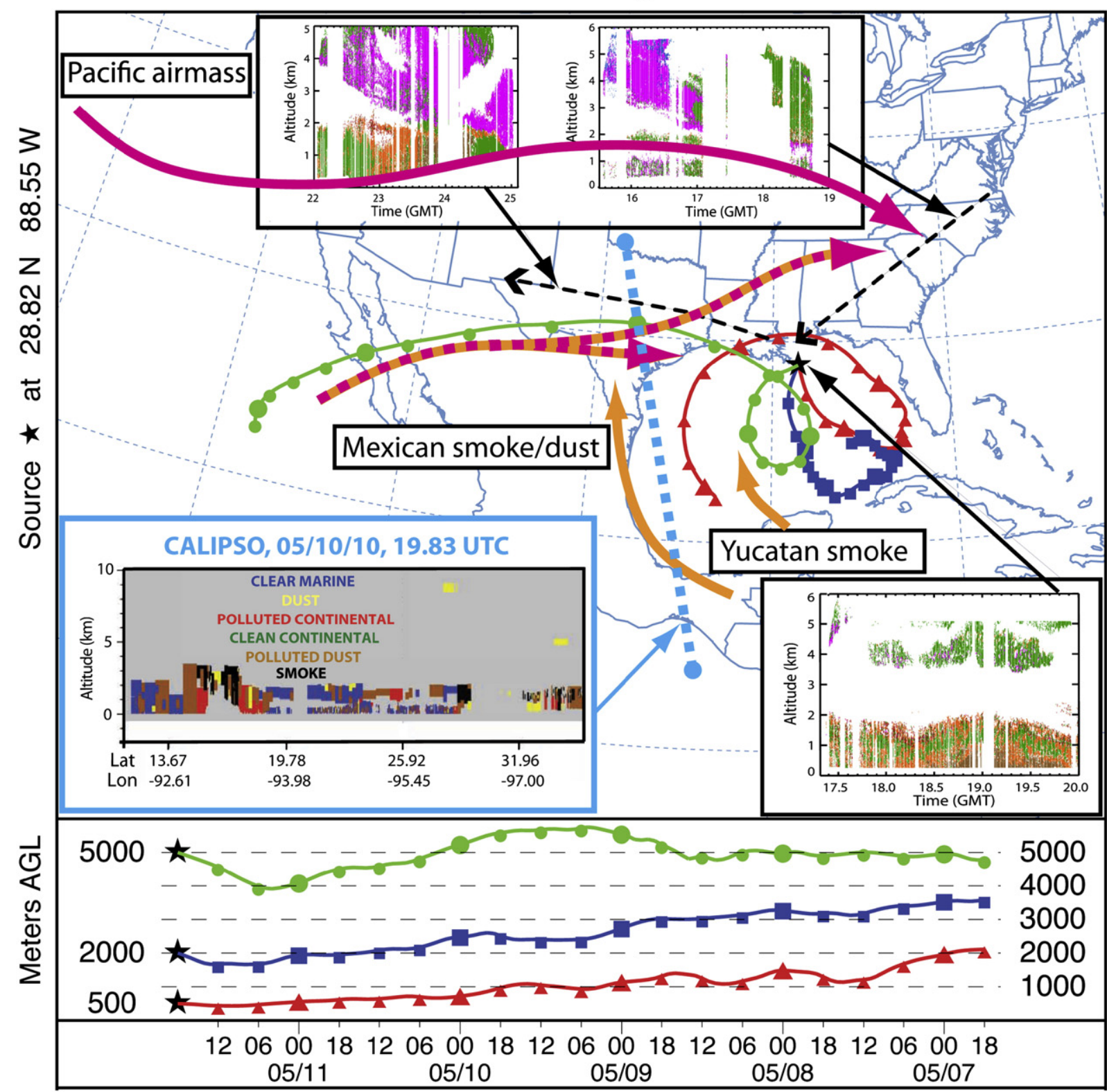

HSRL TYPING

\begin{tabular}{ccccccc} 
Pure & Dusty \\
Dust & Mix & Maritime & $\begin{array}{c}\text { Polluted } \\
\text { Maritime }\end{array}$ Urban & $\begin{array}{c}\text { Fresh } \\
\text { Smoke }\end{array}$ Smoke \\
\hline
\end{tabular}

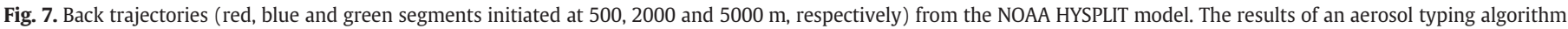

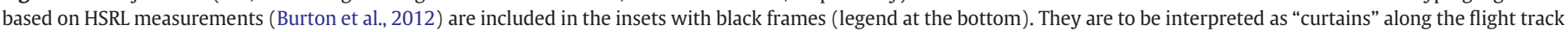

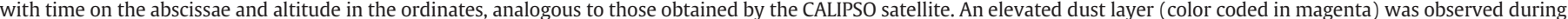

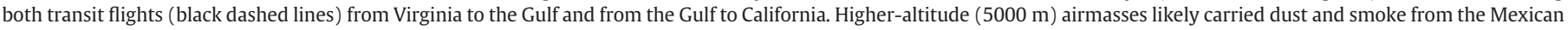

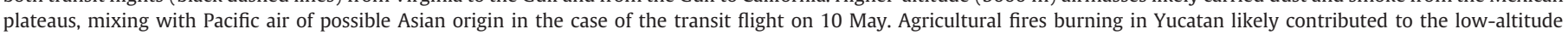

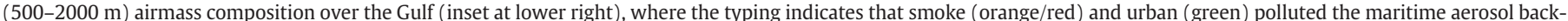

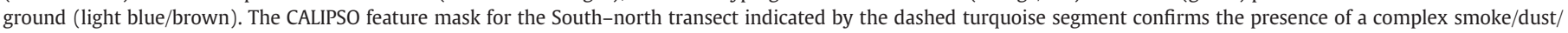
pollution mix over Southern Mexico and the presence of elevated dust over Texas.

site, but the trajectories also suggest that some smoke might have been transported there via a longer and higher-altitude path through the Mexican/US border, possibly being mixed with dust in the process.
These arguments are supported by data from an overpass of the Cloud-Aerosol Lidar and Infrared Pathfinder Satellite Observations (CALIPSO) satellite (Winker et al., 2007, 2009) on 10 May. The 
CALIPSO aerosol subtyping algorithm (Vaughan et al., 2004) successfully detected the complex mix of smoke, pollution and dust near the Southern border of Mexico (see light blue inset in Fig. 7). Also, the same algorithm evidenced elevated dust over Texas as confirmed by the B200 observations. CALIPSO also flew in the early morning of 11 May in near proximity of the Deepwater Horizon platform, effectively resolving the two aerosol layers observed by the HSRL later in the day. The upper one at $4 \mathrm{~km}$ was classified as polluted dust, in agreement with the HSRL. Note, anyway, that this upper layer is optically very thin (the HSRL subtyping algorithm does not use thresholds for the optical thickness). Also, the lowest layer preserves the polluted component although the majority of it is classified as clean marine aerosol by CALIPSO, while the HSRL feature mask offers higher and meaningful speciation into polluted maritime (brown), fresh smoke (orange) and urban components (green).

The highly intricate aerosol situation is likely to be further complicated by the dynamics of oil evaporation. Recent studies identified secondary organic aerosol formation downwind of the Deepwater Horizon site, together with small fractions of oil converted to black carbon (de Gouw et al., 2011). This overall complexity does not affect the primary goal of this study, but together with cirrus clouds above the aircraft it prevented the determination of detailed aerosol microphysics.

\subsection{Cirrus clouds contamination}

Cirrus clouds can form by homogeneous freezing at temperatures below about $-38{ }^{\circ} \mathrm{C}$, but also at warmer temperatures via heterogeneous ice nucleation (Pruppacher \& Klett, 1997). At the location of the observation, HYSPLIT provided values for ambient temperature and relative humidity ranging from $-17{ }^{\circ} \mathrm{C}$ and $54 \%$ at $7 \mathrm{~km}$ to $-24{ }^{\circ} \mathrm{C}$ and $78 \%$ at $8 \mathrm{~km}$. The persistent layer of mineral dust observed in the adjacent days and descending in altitude towards the Gulf could have contributed to nucleation (DeMott et al., 2003). However, MODIS imagery showed a massive synoptic system traversing the continental US from West to East on 11 May. Deep convection, recognized as a major engine for cirrus formation (Sassen et al., 2009), reached an altitude of $15 \mathrm{~km}$ and spanned a region nearly $20^{\circ}$ in latitude over the Midwest at the time of the CALIPSO nighttime overpass (7.92 UTC). By the time of the concurrent B200 observations, the system had shifted its center over the Great Lakes. The ice/water phase classification indeed shows several ice clouds (also visible in Fig. 4) detaching from the outer regions of the storm and descending in altitude towards the Gulf down to $7 \mathrm{~km}$.

The presence of cirrus clouds above the aircraft is a nuisance for RSP retrievals of surface and aerosol properties, because of the uncertainty introduced on the illumination condition; here, it offers the possibility to report on an interesting observation. As discussed in Section 1 , the scaling factor needed to fit the data is likely due to a thin cirrus layer above the aircraft, as also noted in the HSRL operator's notes. At 18.74 UTC, the top panel of Fig. 5 shows an increase of the signal at $1880 \mathrm{~nm}$, which is mostly sensitive to high clouds due to strong water vapor absorption in the lower troposphere at these wavelengths (Gao et al., 2004), but no associated increase in visible reflectance is observed. Inspection of the images collected by the downward-looking camera did also not reveal cloud formations above the visual threshold at 18.74 UTC. Since co-located HSRL measurements confirm high backscatter and depolarization immediately below the B200 down to an altitude of approximately $7300 \mathrm{~m}$, we conclude that the aircraft must have undergone brief incursions in the sparse cirrus cover, of which a fraction was then present under the aircraft. Note that the peaks in the signal at $670 \mathrm{~nm}$ slightly anticipate those at $1880 \mathrm{~nm}$ because, in order to provide visible-channel reflectance that does not suffer from glint contamination, a forward RSP viewing angle well away from the direction of specular reflection had to be used. The $1880 \mathrm{~nm}$ channel is unaffected by the surface due to the heavy attenuation by water vapor, and so the same viewing angle as the DOLP difference could be used.

Again looking at Fig. 5, the step-function-like decrease of the DoLP measured at $2264 \mathrm{~nm}$ due to the water clouds at around 18.65 UTC and 18.68 UTC is clear, and attributed to the relatively high total reflectance of these clouds. However, the effect of the subvisual cirrus at 18.74 UTC on the DoLP is not obvious. Although the portion of this cirrus below the aircraft could partially affect Scene A, it would do so outside the sunglint range of importance for the retrievals discussed in Section 1. Nevertheless, in this section we investigate whether subvisual cirrus beneath the aircraft would influence retrievals of surface refractive index and windspeed if ignored. We first characterize the cirrus cloud properties, and subsequently perform forward simulations to estimate the effect of such clouds on the observed DoLP.

Fig. 8 shows the angular behavior of the $1880 \mathrm{~nm}$ reflectance averaged over 5 RSP scans at 18.74 UTC. The flight trajectory was oriented only $8^{\circ}$ away from the principal plane, so that RSP viewing angles of $-20^{\circ}$ and $20^{\circ}$ correspond to directions very close to specular reflection and backscatter, respectively, as indicated by the top $\mathrm{x}$-axis.

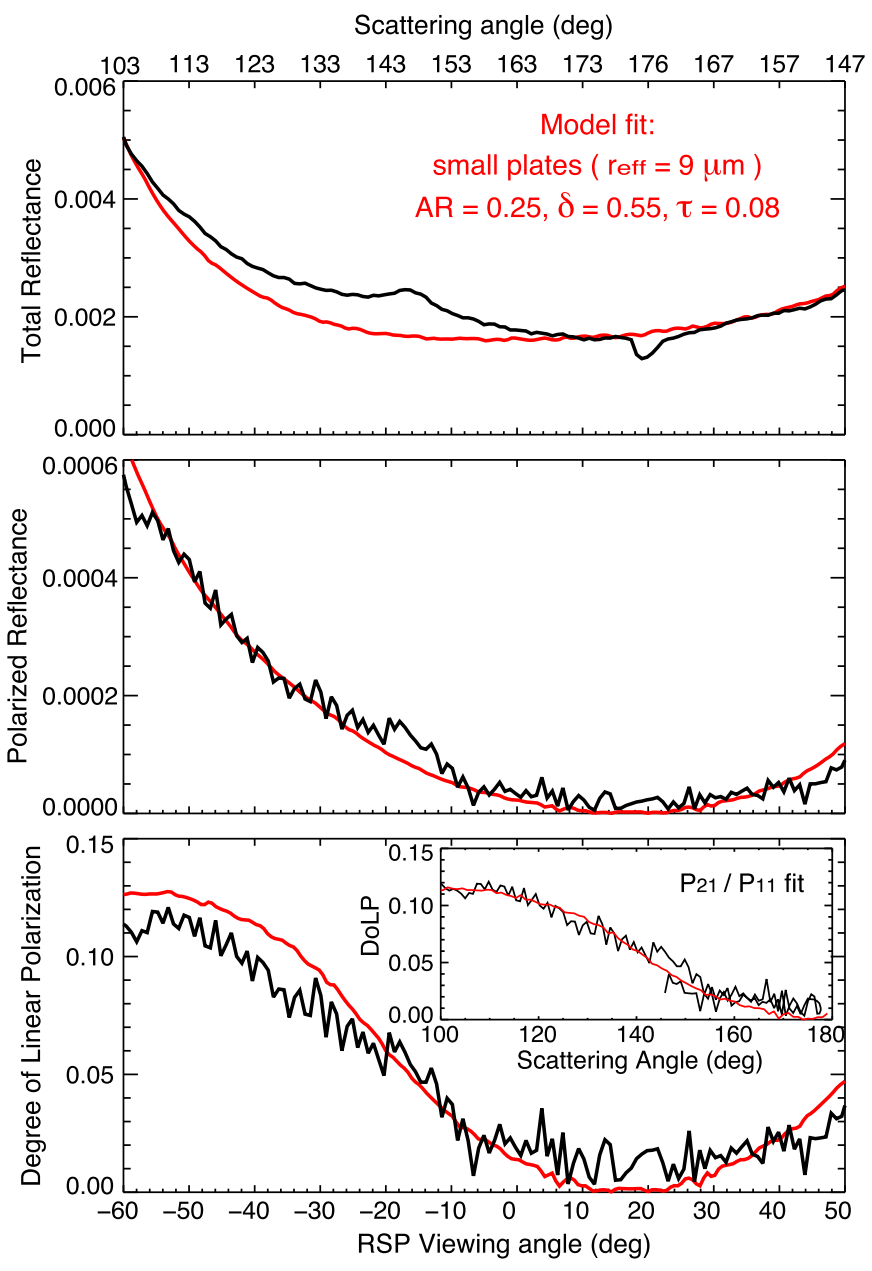

Fig. 8. Data from the RSP channel at $1880 \mathrm{~nm}$ (black lines), usually very dark, revealing presence of cirrus beneath to the aircraft at 18.74 UTC. The x-axes are the same for the three panels, with the top axis converting RSP viewing angles into scattering angles. Top panel: the peak in total reflectance around the direction of specular reflection (scattering angle $\sim 140^{\circ}$ ) is an almost certain indication of horizontally oriented ice crystals. The dip near backscatter is the aircraft shadow. Lower panels: polarized reflectance and degree of linear polarization. The red curves are the RT simulations for a cirrus immediately below the aircraft totaling 0.08 in optical depth, and composed of small ice plates with an effective ratio of $9 \mu \mathrm{m}$, an aspect ratio of 0.25 and roughness parameter of 0.55 . This particle class was selected by minimizing the residuals between the measured DoLP and the $\mathrm{P}_{21} / \mathrm{P}_{11}$ elements of phase matrices computed with a ray-tracing method (inset in the lowest panel). 
The peak in total reflectance (partially recognizable also in the polarized reflectance) was attributed to reflection from a small fraction of Horizontally Oriented Ice (HOI) crystals, and is also known as "subsun" (Borovoi et al., 2007; Brèon \& Dubrulle, 2004; Chepfer et al., 1999; Lavigne et al., 2008; Noel \& Chepfer, 2004). Noel and Chepfer (2010) report that near the tropics oriented crystal are found to occur in $30 \%$ (and up to $50 \%$ at higher latitudes) of the ice clouds forming at temperatures warmer than $-30^{\circ}$, which is consistent with our observations. Note that while the CALIPSO ice/water classification does not exclude the possibility for HOI, this product is too noisy to draw definitive conclusions.

Specular reflection from perfectly horizontal facets is observable only on the principal plane: had the aircraft flown even closer to it, the peak intensity would have been even larger. The small dip near backscatter is instead caused by the shadow of the airplane, unavoidable when flying very close to a target, and that does not carry any polarization signature. This feature would mask any peak found at backscatter due to planar crystals with internal reflections between perpendicular facets (Sherwood, 2005).

Very low lidar depolarization is theoretically expected from HOI, since according to the Fresnel formulae both polarization components have the same reflectivity for perpendicular incidence on a flat surface, while depolarization values found here by the HSRL (20-25\% and above) are similar to those associated with cirrus clouds composed of randomly oriented ice particles. However, minimal deviations from nadir lidar incidence due to varying alignment of the crystals and/or off-nadir pointing of the lidar beam have been shown to be responsible for the loss of the low depolarization characteristic of HOI backscatter (Hu et al., 2007; Noel \& Chepfer, 2010; Noel et al., 2002). The HSRL beam is offset from nadir by $3^{\circ}$ relative to aircraft, and additional deviations follow those of aircraft attitude (mainly pitch, about $2^{\circ}$ in this case); together with possible swinging motions of falling plates, these facts could explain the higher-than-expected depolarization values.

This cirrus was further investigated in order to attempt an estimation of its crystal habit and optical depth. We used geometric optics (Macke et al., 1996) to construct a database with optical properties of single plates and columns with varying sizes, aspect ratios and small-scale roughness parameters (see Macke et al. (1996) for the definition). Plate aspect ratios were varied between 0.1 and 1 with a step size of 0.05 (corresponding reciprocal values are used for columns). Roughness parameters were varied from 0.2 to 0.8 with a step size of 0.05 . Small and large particles with effective radii of about $9 \mu \mathrm{m}$ and $30 \mu \mathrm{m}$, respectively, were included. From this database, the particle class was first selected whose $\mathrm{P}_{21} / \mathrm{P}_{11}$ element of the phase matrix optimally reproduced the degree of linear polarization at $1880 \mathrm{~nm}$ (see inset in the lowest panel of Fig. 8). The DoLP is a convenient modeling choice because it is independent of the optical depth within a singlescattering approximation, which should apply for thin cirrus in the SWIR and can thus be directly compared to the $\mathrm{P}_{21} / \mathrm{P}_{11}$ elements of a modeled phase matrix. At scattering angles larger than about $100^{\circ}$, typical of RSP measurements, distinctive features that facilitate the discrimination among different ice crystal models are an inversion in the sign of polarization near backscatter, and a more or less pronounced modulation at side-scattering angles. These structures are suppressed in presence of irregular crystal habits, small-scale surface roughness, or by inclusion of air bubbles (Baran, 2009). A change in sign in $\mathrm{Q}$ would manifest as a discontinuity at the minimum for the polarized reflectance $\left(R_{p}=\sqrt{R_{Q}^{2}+R_{U}^{2}}\right)$, but this feature is absent near backscatter, where the signal smoothly declines toward zero. This fact, together with the smooth increase toward side-scattering angles, points to the dominant presence of roughened particles. The optimal fit was obtained for small ice plates (effective radius $\sim 9 \mu \mathrm{m}$ ) characterized by an aspect ratio $A R=0.25$ and a roughness parameter $\delta=0.55$. This roughness parameter is close to values generally found from analyses of global POLDER data (Baran \& Labonnote, 2006;
Knap et al., 2005). Interestingly, the obtained effective radius and aspect ratio correspond reasonably well with those $(8.82 \mu \mathrm{m}$ and 0.17 , respectively) found by Lawson et al., (2008) using in situ measurements, although they probed subvisual cirrus at much colder temperatures.

The particle number concentration (between 7300 and $7800 \mathrm{~m}$ to simulate the cirrus) was then adjusted in the forward radiative transfer model to simultaneously fit the total reflectance, leading to an optical depth of 0.08 . This value places the observed cirrus in the threshold-visible category (Sassen \& Cho, 1992), where actual visibility depends on illumination conditions that in our case did not make the cloud perceivable to the naked eye. Anyway, the important point is that this result is encouraging because of the difficulty in detecting cirrus clouds of such small optical depths which are nonetheless suspected to have important effects on climate (McFarquhar et al., 2000). The fit to the polarized reflectance is remarkable. The fit to the total reflectance is also satisfactory, considering that the model does not simulate the specular peak. A slight underestimation of this signal at side-scattering $\left(<140^{\circ}\right)$ angles results in a small degradation in the quality of the fit to the DoLP, compared to the fit to $\mathrm{P}_{21} / \mathrm{P}_{21}$ used to select the particle class from the phase matrix database.

A final remark on the retrieved optical depth concerns the scaling factor found in Section 1 for the total reflectance (0.92), attributed to cirrus over the aircraft as noted by the operator. The corresponding optical depth obtained by applying Lambert-Beer's law is about 0.08 , that is, the same optical thickness retrieved for the cirrus overflown less than a minute before and discussed in this section. A sensible explanation for this match is that the B200 was traversing whiskers of cirrus clouds of similar optical depths, sometimes overflying and sometimes underflying their thickest portions.

The optical and microphysical properties of the cirrus cloud determined above were used to model the effect of a cirrus cloud beneath the aircraft on the DoLP at $2264 \mathrm{~nm}$, for a viewing geometry and ocean state (no oil included) similar to those characterizing the observations on 11 May. It was found that, in the glint region, a $1 \%(15 \%)$ decrease in the DoLP requires a cirrus optical depth of 0.14 (0.7). No appreciable differences in DoLP are therefore expected to be caused by thin cirrus clouds, as confirmed by the absence in Fig. 5 of a sudden drop in DoLP associated with this particular cirrus.

In summary, it is likely that roughened ice crystals formed in the outflow of a large system were descending under the effect of gravity before sublimating. A small percentage of oriented plates explains the appearance of a measurable specular reflection peak; swinging motions during the fall would then be responsible for the angular broadening of the peak, for attenuating its polarized reflectance, and for the lack of low lidar depolarization. Forward simulation showed that no appreciable differences in DoLP are expected to be caused by thin cirrus clouds, so the retrieved surface refractive index and windspeed should be unaffected by cirrus contamination.

\section{Conclusions}

This work presents the straightforward application of a technique based on first principles, namely the Fresnel formulae, to detect variations of surface optical properties. The method exploits sunglint, a highly directional feature that can be modeled with satisfactory accuracy by current (in fact, more than 50 years old) models. More specifically, variations in the degree of linear polarization in the sunglint region are indicative of changes in the refractive index caused by the presence of an oil sheen on ocean waters. From a remote sensing perspective, the success of this technique is yet another example of the usefulness of a polarization channel in the SWIR, a unique feature of the GISS Research Scanning Polarimeter.

For the case analyzed here, a survey over the Deepwater Horizon oil spill site three weeks after the well-known disaster, it is found that the oil altered the surface optical and physical properties by 
both affecting the refractive index and suppressing the capillary waves. The latter effect is manifested in the reduction of the apparent wind speed which is part of the presented retrievals.

Operationally, straight-and-level transects closely aligned with the principal plane of reflection can be flown to map the extent of the spill, preferably in clear (i.e., cirrus-free) conditions. An estimation of the absolute value of the refractive index is possible, but its accuracy is linked to optimal flight attitude. While fulfilling this condition can be challenging with small aircraft, it can be mitigated by flying larger sub-orbital platforms at low altitudes, and is of special interest in perspective of satellite missions with polarization capabilities, for which attitude instabilities are virtually absent. For well-established oil slicks observed in more favorable conditions than those presented here, further investigations could be aimed at estimating the thickness of a slick, crucial for the evaluating the evolution of a spill and its impacts on the ecosystem.

Spatial variability and a vast assortment of aerosol types on 11 May prevented us from running the inversion scheme including a full set of aerosol microphysical parameters, but this does not affect the results since the surface contribution is successfully isolated. A simple approximation was used to constrain the retrieval with the aerosol amount measured by the HSRL, to improve the fit to the RSP observations at off-glint angles, therefore outside the range significant for the inversion.

Additional noteworthy results include the good agreement found between CALIPSO and HSRL typing products, providing context for the analyzed scenes, and the detection of horizontally-aligned ice plate signatures in some of the cirrus clouds overflown by the RSP. As expected, the band at $1880 \mathrm{~nm}$ proved adequate in estimating low optical thicknesses close to the visual threshold (0.08) which, as is the case for aerosols, do not appreciably affect the variations in degree of linear polarization in the glint exploited in the retrievals of the surface properties.

\section{Acknowledgments}

Matteo Ottaviani was supported by an appointment to the NASA Postdoctoral Program at the NASA Goddard Institute for Space Studies, administered by Oak Ridge Associated Universities through a contract with NASA. A special mention must be given to the pilots (Mike Wusk, Rick Yasky, Les Kagey) and the ground crew (Rob White, Dale Bowser) of the B200 for their outstanding dedication, not limited to the research flights described in the present work. M. Ottaviani also thanks Misha Alexandrov for his insightful feedback on the analysis of the data. Mark Dix, Bill Lehr and CJ Beegle-Krause at NOAA need be mentioned, together with A. Stelmaszewski and T. Kròl, for the interest they demonstrated in the RSP measurements and for their contribution on "missing" refractive index data for crude oil. The NOAA Air Resources Laboratory (ARL) is gratefully acknowledged for the provision of the HYSPLIT transport and dispersion model through the READY website (http://www.arl.noaa.gov/ready.php), together with the NASA/GSFC, MODIS Rapid Response team (Jeff Schmaltz especially) for the MODIS imagery available at http://rapidfire.sci.gsfc.nasa.gov. These two portals are excellent examples of user-friendliness and were of great value in building scene context for this publication.

\section{Appendix A. Optical signatures of thin-film interference}

Interference patterns caused by thin films are responsible for the iridescent colors observed everyday in soap bubbles or fuel on asphalt, and are exploited for technological purposes in the construction of anti-reflective coatings and interferometers. Calculation of the intensity of the fringes and their spacing is a classical exercise in fundamental optics (Born \& Wolf, 1999). This section applies a simple model to describe the theoretical effects of film thickness on the observed reflectance.
Fringes of equal inclination (or Heidinger fringes when observing at near-normal incidence) are formed when a non-parallel bundle of rays strike a surface, and require an imaging lens focused at infinity. Rays emerging from different points at the surface but reflected towards the detector at the same angle are imaged in different regions of the detector, as a function of the incident angle. When the source is moved at great distance or anyway collimated, fringes of equal thickness (or Fizeau fringes when observing at normal incidence) are instead observed at a single angle as different wavelengths experience different path lengths within the film. They can be interpreted as a contour map, with isolines connecting points of equal thickness. This latter case is what can potentially be observed by the RSP. When illumination comes from a broadband source, at appropriate film thicknesses the fringes assume bright rainbow colors.

In our context, solar radiation is incident on the water surface from the air above. If the water surface is coated by a substance with a different refractive index, two interfaces (top and bottom) are created. Electromagnetic waves reflected off the top interface interfere with those penetrating in the film, reflecting at the bottom interface, and then emerging back in air. The additional path length experienced by the waves traveling in the film determines the amount of interference. The refraction angle $\theta_{t}$ is connected to the incidence angle $\theta_{i}$ via Snell's law. Given a certain thickness $d$ of oil with a refractive index $n_{\text {oil }}$, and if $n_{\text {air }}=1$, maximum (minimum) interference occurs when the path length $2 \mathrm{~d} \cos \theta_{\mathrm{t}}$ is equal to an odd (even) number of half-wavelengths:

$$
(2 m-1) \frac{\lambda_{\max }}{2}=2 n_{\text {oil }} \mathrm{d} \cos \theta_{\mathrm{t}}
$$

$2 m \frac{\lambda_{\min }}{2}=2 n_{\text {oil }} \mathrm{d} \cos \theta_{\mathrm{t}}$

The positive integer $m$ is the order of interference, and the equations above account for the additional phase shift of $\pi$ experienced by waves reflected at the top interface because they impinge on a medium of higher reflective index. Since oil has typically higher refractive index than water, this phase shift does not apply to the waves reflecting from the bottom interface. Between these maxima and minima, the intensity oscillates according to the relative phase shift and can be calculated applying the principle of superposition to the amplitude components perpendicular and parallel to the plane of incidence (see, for example, http://laser.physics.sunysb.edu/ ett/report/). The reflection coefficient is different for the two components and varies with the angle of incidence, as predicted by the Fresnel equations. Nonetheless, this difference disappears in conditions of normal incidence at which the reflectivity is $R=\left[\left(1-n_{\text {oil }}\right) /\left(1+n_{\text {oil }}\right)\right]^{2}$ and the intensity as a function of wavelength and thickness assumes the relatively simple form:

$$
\frac{I(\lambda, d)}{I_{0}}=R\left[2-R^{2}+2 \sqrt{1-R^{2}} \cos \left(\frac{4 \pi n_{\text {oil }} d}{\lambda}-\pi\right)\right]
$$

A similar expression, albeit in transmittance, was obtained by Huibers \& Shah, (1997). In the simulations we have employed a constant, plausible refractive index for oil $n_{\mathrm{oil}}=1.48$, normal incidence conditions (overhead sun and nadir observation), and assumed that the solar radiation is white in the visible with irradiance $I_{0}$. In Fig. $1 \mathrm{~A}$, the contour plot of the normalized intensity $I / I_{0}$ clearly shows the first different orders of interference that could cause differential reflectance and therefore observable colors in the visible. Details are better understood looking at some horizontal and vertical sections (lower panels).

All wavelengths experience destructive interference when the thickness approaches zero, which also poses a limit for thickness measurements to a few tens of nanometers. Taking as representative a triplet of RGB wavelengths, we observe how the silvery appearance of a sheen with $n_{\mathrm{oil}}=1.48$ is justified as the thickness grows to $75 \mathrm{~nm}$, 

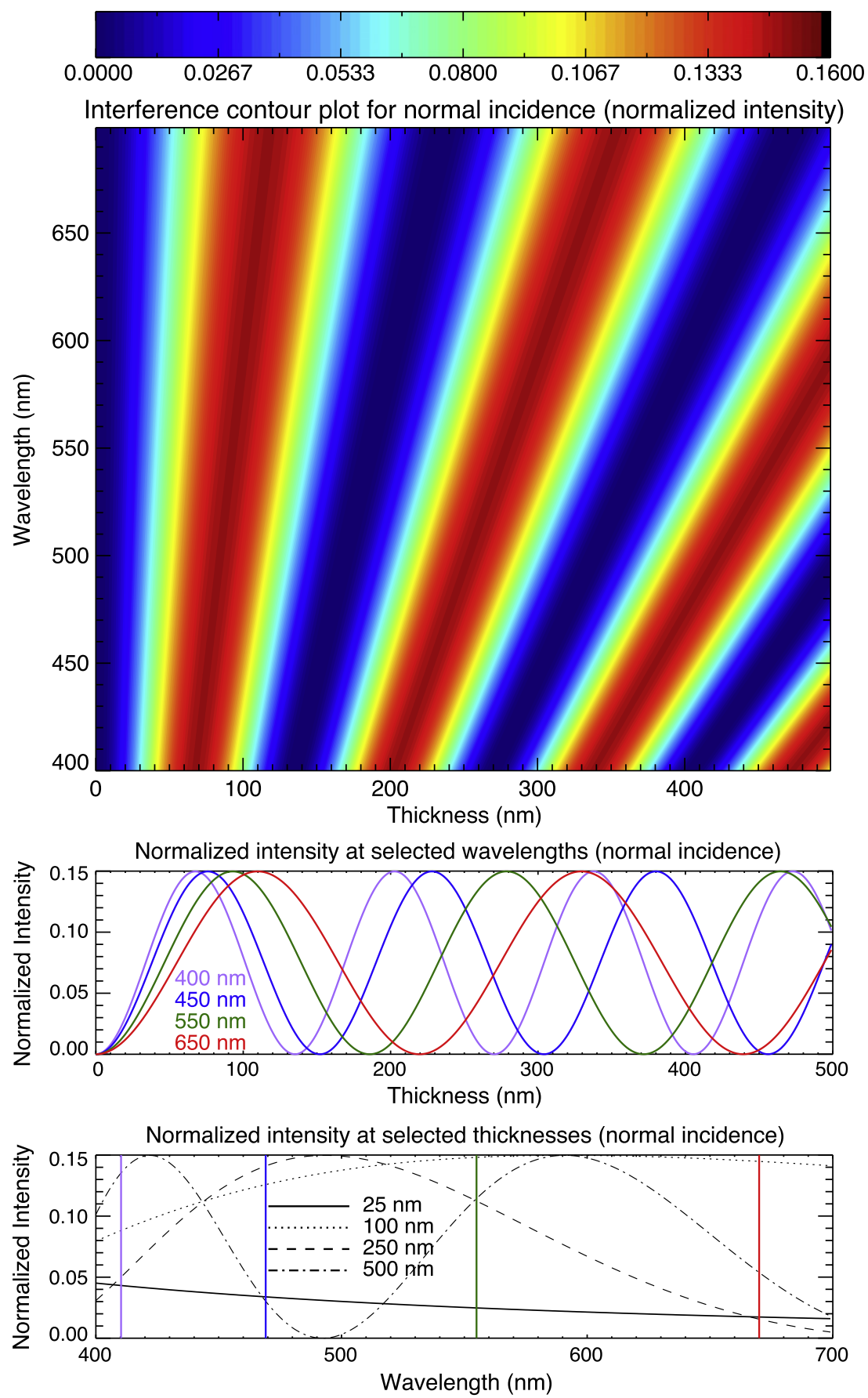

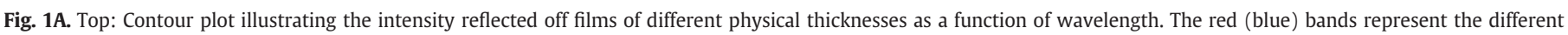

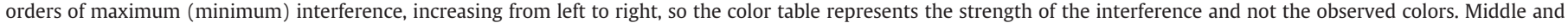

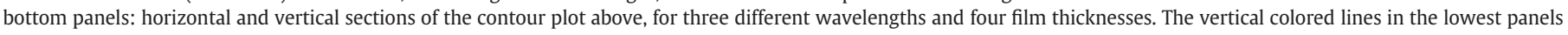
coincide with the center-bands of the RSP channels in the visible (see Section 2).

because the intensity increases similarly for all wavelengths. Dark colors are expected at around $150 \mathrm{~nm}$, but it is for thickness values of approximately $200 \mathrm{~nm}$, and onward to values comparable to the visible wavelengths, that the brightest colors appear as a result of large differences in reflected intensity for the different wavelengths. Finally, note how the intensity peaks have equal maxima, since we have not considered absorption in the film.

The actual color theoretically observed by the human eye is "modeled" in the lowest panel for four thickness values. The dark appearance of a very thin layer is shown by the curve for $25 \mathrm{~nm}$. At $100 \mathrm{~nm}$, almost all wavelengths have high reflectance (although the decrease in the blue might leave an orange hue). The case of a
$250 \mathrm{~nm}$-thick film can be taken as good example for a film showing a decisive blue-green tint, while $500 \mathrm{~nm}$ are expected to depress that very same color promoting red and violet hues. In this plot we have also indicated with vertical colored bars the location of the RSP bands in the visible, which can in principle be exploited to detect such oscillations.

\section{References}

Al'perovich, L. I., Komarova, A. I., Narziev, B. N., \& Pushkarev, V. N. (1978). Optical constants of petroleum samples in the $0.25-25 \mu$ range. Journal of Applied Spectroscopy, 28, 491-494. doi:10.1007/BF00608110 
Baran, A. (2009). A review of the light scattering properties of cirrus. Journal of Quantitative Spectroscopy and Radiative Transfer, 110(14-16), 1239-1260.

Baran, A., \& Labonnote, L. (2006). On the reflection and polarisation properties of ice cloud. Journal of Quantitative Spectroscopy and Radiative Transfer, 100(1-3), 41-54.

Born, M., \& Wolf, E. (1999). Principles of optics (7th Edition). Cambridge University Press.

Borovoi, A., Burnashov, A., \& Cheng, A. (2007). Light scattering by horizontally oriented ice crystal plates. Journal of Quantitative Spectroscopy and Radiative Transfer, 106(1-3), 11-20 IX Conference on Electromagnetic and Light Scattering by NonSpherical Particles.

Brekke, C., \& Solberg, A. (2005). Oil spill detection by satellite remote sensing. Remote Sensing of Environment, 95(1), 1-13.

Brèon, F. -M., \& Dubrulle, B. (2004). Horizontally oriented plates in clouds. Journal of the Atmospheric Sciences, 61(23), 2888-2898.

Burton, S. P., Ferrare, R. A., Hostetler, C. A., Hair, J. W., Rogers, R. R., Obland, M. D., et al. (2012). Aerosol classification of airborne high spectral resolution lidar measurements-1. Methodology and examples. Atmospheric Measurement Techniques, 5, 73-98.

Cairns, B., Russell, E., LaVeigne, J., \& Tennant, P. (2003). Research scanning polarimeter and airborne usage for remote sensing of aerosols. Proceedings of SPIE, Vol. 5158. (pp. 33-44).

Cairns, B., Russell, E., \& Travis, L. (1999). Research scanning polarimeter: Calibration and ground-based measurements. Society of Photo-Optical Instrumentation Engineers (SPIE) Conference Series., 3754, 186-196.

Chepfer, H., Brogniez, G., Goloub, P., Breon, F., \& Flamant, P. (1999). Observations of horizontally oriented ice crystals in cirrus clouds with POLDER-1/ADEOS-1. Journal of Quantitative Spectroscopy and Radiative Transfer, 63, 521-543.

Chowdhary, J., Cairns, B., Mishchenko, M., Hobbs, P., Cota, G., Redemann, J., et al. (2005). Retrieval of aerosol scattering and absorption properties from photopolarimetric observations over the ocean during the CLAMS experiment. Journal of the Atmospheric Sciences, 62(4), 1093-1117.

Clark, R., Swayze, G., Leifer, I., Livo, K., Lundeen, S., Eastwood, M., et al. (2010). A method for qualitative mapping of thick oil spills using imaging spectroscopy. U.S. Geological Survey Open-File Report 2010-1167. USGS 51 p.

Cox, C., \& Munk, W. (1954). Measurement of the roughness of the sea surface from photographs of the sun's glitter. Journal of the Optical Society of America, 44(11), 838-850.

Cox, C., \& Munk, W. (1956). Slopes of the sea surface deduced from photographs of sun glitter. Bull. Scripps Inst. Oceanogr, 6(9), 401-488.

de Gouw, J. A., Middlebrook, A. M., Warneke, C., Ahmadov, R., Atlas, E. L., Bahreini, R., et al. (2011). Organic aerosol formation downwind from the deepwater horizon oil spill. Science, 331(6022), 1295-1299.

De Haan, J., Bosma, P., \& Hovenier, J. (1987). The adding method for multiple scattering calculations of polarized light. Astronomy and Astrophysics, 183(2), 371-391 ISSN.

DeMott, P., Cziczo, D., Prenni, A., Murphy, D., Kreidenweis, S., Thomson, D., et al. (2003). Measurements of the concentration and composition of nuclei for cirrus formation. Proceedings of the National Academy of Sciences of the United States of America, $100(25), 14655$

den Boer, J. H. W. G., Kroesen, G. M. W., \& de Hoog, F. J. (1995). Measurement of the complex refractive index of liquids in the infrared using spectroscopic attenuated total reflection ellipsometry: Correction for depolarization by scattering. Applied Optics, 34(25), 5708-5714.

Draxler, R., \& Rolph, G. (2010). HYSPLIT (HYbrid Single-Particle Lagrangian Integrated Trajectory) model. access via NOAA ARL READY Website. http://www.arl.noaa. gov/ready/hysplit4.html NOAA Air Resources Laboratory, Silver Spring, MD.

Farmer, D., \& Li, M. (1994). Oil dispersion by turbulence and coherent circulations. Ocean Engineering, 21(6), 575-586.

Gao, B., \& Kaufman, Y. (2003). Water vapor retrievals using Moderate Resolution Imaging Spectroradiometer (MODIS) near-infrared channels. Journal of Geophysical Research, 108(D13), 4389.

Gao, B., Meyer, K., \& Yang, P. (2004). A new concept on remote sensing of cirrus optical depth and effective ice particle size using strong water vapor absorption channels near 1.38 and $1.88 \mu \mathrm{m}$. IEEE Transactions on Geoscience and Remote Sensing, 42(9), 1891-1899.

Goodman, R. (1994). Overview and future trends in oil spill remote sensing. Spill Science Er Technology Bulletin, 1(1), 11-21.

Hair, J., Hostetler, C., Cook, A., Harper, D., Ferrare, R., Mack, T., et al. (2008). Airborne High Spectral Resolution Lidar for profiling aerosol optical properties. Applied Optics, 47(36), 6734-6752.

Halthore, R., Eck, T., Holben, B., \& Markham, B. (1997). Sun photometric measurements of atmospheric water vapor column abundance in the $940-\mathrm{nm}$ band. Journal of Geophysical Research, 102(D4), 4343-4352.

Hansen, J., \& Travis, L. (1974). Light scattering in planetary atmospheres. Space Science Reviews, 16(4), 527-610.

Harvey, A., Gallagher, J., \& Levelt Sengers, J. (1998). Revised formulation for the refractive index of water and steam as a function of wavelength, temperature, and density. Journal of Physical and Chemical Reference Data, 27(4), 761-774.

Hu, Y., Vaughan, M., Liu, Z., Lin, B., Yang, P., Flittner, D., et al. (2007). The depolarizationattenuated backscatter relation: CALIPSO lidar measurements vs. theory. Optics Express, 15(9), 5327-5332.

Huibers, P., \& Shah, D. (1997). Multispectral determination of soap film thickness. Langmuir, 13(22), 5995-5998.

Knap, W., C-Labonnote, L., Brogniez, G., \& Stammes, P. (2005). Modeling total and polarized reflectances of ice clouds: Evaluation by means of POLDER and ATSR-2 measurements. Applied Optics, 44(19), 4060-4073.

Knobelspiesse, K., Cairns, B., Ottaviani, M., Ferrare, R., Hair, J., Hostetler, C., et al. (2011). Combined retrievals of boreal forest fire aerosol properties with a polarimeter and lidar. Atmospheric Chemistry and Physics Discussions, 11(3), 7909-7969.
Król, T., Stelmaszewski, A., \& Freda, W. (2006). Variability in the optical properties of a crude oil-seawater emulsion. Oceanologia, 48, 203-211 (S).

Lacis, A., \& Oinas, V. (1991). A description of the correlated k distributed method for modeling nongray gaseous absorption, thermal emission, and multiple scattering in vertically inhomogeneous atmospheres. Journal of Geophysical Research, 96, 9027-9063.

Lavigne, C., Roblin, A., \& Chervet, P. (2008). Solar glint from oriented crystals in cirrus clouds. Applied Optics, 47(33), 6266-6276.

Lawson, R., Pilson, B., Baker, B., Mo, Q., Jensen, E., Pfister, L., et al. (2008). Aircraft measurements of microphysical properties of subvisible cirrus in the tropical tropopause layer. Atmospheric Chemistry and Physics, 8(6), 1609-1620.

Lehr, W., \& Simecek-Beatty, D. (2000). The relation of Langmuir circulation processes to the standard oil spill spreading, dispersion, and transport algorithms. Spill Science \& Technology Bulletin, 6(3), 247-254.

Macke, A., Mueller, J., \& Raschke, E. (1996). Single scattering properties of atmospheric ice crystals. Journal of the Atmospheric Sciences, 53(19), 2813-2825.

Markwardt, C. B. (Sep. 2009). Non-linear least-squares fitting in IDL with MPFIT. In D. A. Bohlender, D. Durand, \& P. Dowler (Eds.), Astronomical Data Analysis Software and Systems XVIII. Vol. 411 of Astronomical Society of the Pacific Conference Series pp. 251-+

Masuda, K. (1998). Effects of the speed and direction of surface winds on the radiation in the atmosphere-ocean system. Remote Sensing of Environment, 64(1), 53-63.

McFarquhar, G., Heymsfield, A., Spinhirne, J., \& Hart, B. (2000). Thin and subvisual tropopause tropical cirrus: Observations and radiative impacts. Journal of the atmospheric sciences, 57(12), 1841-1853.

Mishchenko, M., \& Travis, L. (2008). Gustav mie and the evolving discipline of electromagnetic scattering by particles. Bulletin of the American Meteorological Society, 89(12), 1853-1861.

Moré, J. (March 1978). The Levenberg-Marquardt algorithm: Implementation and theory In G. Watson (Ed.), Numerical Analysis:s: Proceedings of the Biennial Conference Held at Dundee, June 28-July 1, 1977. Vol. 630 of Lecture Notes in Mathematics. (pp. 105-116). Springer Verlag.

Noel, V., \& Chepfer, H. (2004). Study of ice crystal orientation in cirrus clouds based on satellite polarized radiance measurements. Journal of the Atmospheric Sciences, 61(16), 2073-2081.

Noel, V., \& Chepfer, H. (2010). A global view of horizontally oriented crystals in ice clouds from Cloud-Aerosol Lidar and Infrared Pathfinder Satellite Observation (CALIPSO). Journal of Geophysical Research, 115 (null).

Noel, V., Roy, G., Bissonnette, L., Chepfer, H., \& Flamant, P. (2002). Analysis of lidar measurements of ice clouds at multiple incidence angles. Geophysical Research Letters, 29(9) 52-1.

Nunziata, F., Gambardella, A., \& Migliaccio, M. (2008). On the Mueller scattering matrix for SAR sea oil slick observation. Geoscience and Remote Sensing Letters, IEEE, 5(4), 691-695.

Oil Budget Calculator Science and Engineering Team. (November 2010). Oil Budget Calculator, Deepwater Horizon. Technical report, The Federal Interagency Solutions Group.

Otremba, Z. (2000). The impact on the reflectance in VIS of a type of crude oil film floating on the water surface. Optics Express, 7(3), 129-134.

Otremba, Z., \& Piskozub, J. (2003). Modeling the remotely sensed optical contrast caused by oil suspended in the sea water column. Optics Express, 11(1), 2-6.

Ottaviani, M., Merck, C., Long, S., Koskulics, J., Stamnes, K., Su, W., et al. (2008a). Timeresolved polarimetry over water waves: Relating glints and surface statistics. Applied Optics, 47(10), 1638-1648.

Ottaviani, M., Spurr, R., Stamnes, K., Li, W., Su, W., \& Wiscombe, W. (2008b). Improving the description of sunglint for accurate prediction of remotely sensed radiances. Journal of Quantitative Spectroscopy and Radiative Transfer, 109(14), 2364-2375.

Ottaviani, M., Stamnes, K., Koskulics, J., Eide, H., Long, S., Su, W., et al. (2008c). Light reflection from water waves: Suitable setup for a polarimetric investigation under controlled laboratory conditions. Journal of Atmospheric and Oceanic Technology, 25(5), 715-728.

Pruppacher, H., \& Klett, J. (1997). Microphysics of clouds and precipitation. Dordrecht and Boston: Kluwer Academic Publishers.

Rodgers, C. (September 2000). Inverse methods for atmospheric sounding theory and practice. Vol. 2 of Series on atmospheric, oceanic and planetary physics. World Scientific Publishing Company.

Rogers, R., Hair, J., Hostetler, C., Ferrare, R., Obland, M., Cook, A., et al. (2009). NASA LaRC airborne high spectral resolution lidar aerosol measurements during MILAGRO: Observations and validation. Atmospheric Chemistry and Physics Discussions, 9(2), 8817-8856.

Rothman, L., Barbe, A., Chris Benner, D., Brown, L., Camy-Peyret, C., Carleer, M., et al. (2003). The HITRAN molecular spectroscopic database: Edition of 2000 including updates through 2001. Journal of Quantitative Spectroscopy and Radiative Transfer, $82(1-4), 5-44$.

Sassen, K., \& Cho, B. (1992). Subvisual-thin cirrus lidar dataset for satellite verification and climatological research. Journal of Applied Meteorology, 31, 1275-1285.

Sassen, K., Wang, Z. \& Liu, D. (2009). Cirrus clouds and deep convection in the tropics: Insights from CALIPSO and CloudSat. Journal of Geophysical Research, 114, D00H06.

Shaw, J. A. (1999). Degree of linear polarization in spectral radiances from waterviewing infrared radiometers. Applied Optics, 38, 3157-3165.

Shaw, J. A. (2001). Polarimetric measurements of long-wave infrared spectral radiance from water. Nov. Appl. Opt., 40(33), 5985-5990 URL. http://ao.osa.org/abstract. $\mathrm{cfm}$ ?URI $=$ ao- $40-33-5985$

Sherwood, S. (2005). Detection of faceted crystals in deep convective clouds via the antisolar peak. Journal of Geophysical Research, 110(D14), D14205. 
Stam, D., De Haan, J., Hovenier, J., \& Stammes, P. (1999). Degree of linear polarization of light emerging from the cloudless atmosphere in the oxygen A band. Journal of Geophysical Research, 104, 16.

Thorpe, S. A. (2000). Langmuir circulation and the dispersion of oil spills in shallow seas. Spill Science E Technology Bulletin, 6(3-4), 213-223.

Vaughan, M., Young, S., Winker, D., Powell, K., Omar, A., Liu, Z., et al. (2004). Fully automated analysis of space-based lidar data: An overview of the CALIPSO retrieval algorithms and data products. Proc. of SPIE, Vol. 5575. (pp. 17).
Winker, D., Hunt, W., \& McGill, M. (2007). Initial performance assessment of CALIOP. Geophysical Research Letters, 34(19), L19803.

Winker, D. M., Vaughan, M. A., Omar, A., Hu, Y., Powell, K. A., Liu, Z., et al. (2009). Overview of the CALIPSO mission and CALIOP data processing algorithms. Journal of Atmospheric and Oceanic Technology, 26(11), 2310-2323. 